\title{
High and Low Activity Spells in Housing Markets
}

\author{
Eric Smith* \\ University of Essex
}

June 2019

\begin{abstract}
This paper demonstrates the way in which stock-flow matching with endogenous seller entry generates hot and cold spells in house sales. Potential sellers know the number of bidders remaining from the last house sale. If two or more bidders remain, the seller obtains the gains to trade through competitive bidding. The market is active. With one monopolistic bidder, the buyer captures the surplus and sellers become unwilling to enter. The market remains inactive until sellers think enough time has passed for buyer entry to have replenished the market and make entry profitable. The resulting pattern of trade matches up with observations from Dane County, Wisconsin.
\end{abstract}

Keywords: Stock-flow matching, sales fluctuations, price fluctuations, time on the market. JEL Classification: E30, R31, R21.

\footnotetext{
${ }^{*}$ Correspondence: Department of Economics, University of Essex, Wivenhoe Park, Colchester, CO4 3SQ, UK.
} Telephone: +441206872758. Fax: +441206872724. Email: esmith@essex.ac.uk 


\section{Introduction}

Housing markets, like labor and other markets with trading frictions, often appear to experience prolonged spells of high and low turnover. Although details vary across markets and over time, the general finding is that during high volume periods, prices are high and the time to trade short. When turnover becomes slack, prices are low, if exchange occurs at all, and traders spend a seemingly long time on the market. As a result, prices and sales become variable, contemporaneously correlated, and persistent.

This paper demonstrates the way in which such distinct hot and cold trading episodes can arise given a stock-flow matching process. The paper characterizes the way in which these cycles vary with trading conditions and then investigates the impact these fluctuating spells can have on observed prices, sales and time to sale. The paper assesses this impact with comparisons to observed measures in the residential property market in Madison, Wisconsin.

Stock-flow matching (see Taylor, 1995; Coles and Smith, 1998; Coles and Muthoo, 1998; Lagos, 2000) assumes that buyers and sellers do not search randomly. Instead, market participants have a good idea about where to look for suitable partners. They check public and private intermediaries such as real estate agencies and websites. Although these trading platforms provide information on a wide variety of opportunities, traders look for very specific characteristics. Stock-flow buyers and sellers trade in precise, distinct markets, differentiated by location and other features in which there are no trading frictions. In the housing market context, multiple markets exist in a local geographic region. Within each small market, buyers look for a combination of rooms, acreage, amenities and so on.

As buyers randomly come and go in each particular market, the populations fluctuate so that traders can be on either the long or the short side of their precise market. If lucky, an entrant is on the short side and finds one or more options immediately available. Trade occurs straightaway. If the entrant is unlucky and on the long side, there are no potential partners immediately at hand. In the event that no partners currently exist, the entrant becomes a part of the stock or queue of traders on their side of the market and must wait to match from the flow of new entrants on the other side.

The innovation introduced into the model here is to allow endogenous seller entry. To maintain a well behaved market over time, the stock-flow literature typically assumes that buyers and sellers independently enter the market one by one at the same exogenous Poisson rate. In this paper, sellers have a higher arrival rate than buyers but they have the option to decline the opportunity to enter the market and save the associated sunk cost of participation.

To illustrate, consider a housing market in which buyers bid for available homes in a public, complete information auction. Suppose a potential house seller contemplating putting a home on the market is "relaxed." For example, some home owners have the option to wait and consider moving later. If the seller knows that two or more bidders are willing to make offers, it will pay the up-front cost of moving or building the house knowing that Bertrand bidding from the buyers will result in the seller obtaining most of the gains to trade. On the other hand, with one or zero bidders present, the seller will face a monopolistic buyer (either immediately or in the future) who captures the majority of the gains to trade. Entry does not occur in this case 
as the seller does not recover its up-front costs.

Sellers know the number of bidders, to some extent, from the previous auction. If there were $N+1$ bidders in the last auction, there must be at least $N$ for the next. As such, sellers will enter until only one known bidder remains. The market then goes quiet and house sellers forgo the opportunity to enter the market. As time passes, buyer entry will gradually replenish the market. Assuming buyer entry is not revealed until the next auction is held, the market remains dormant until sellers think enough time has passed to make it profitable to enter the market. When the market re-activates, if new buyer entry did not occur, the lone bidder left at the last auction pays a low price and the market becomes dormant yet again, even more so as replenishing now requires not one but two new buyers. If buyer entry occurred, the bidders offer high prices and entry remains active until the queue of buyers dwindles down again.

This pattern of trade is inefficient. When entry gets turned off with one bidder known to be waiting, gains to trade are passed over. A bidder exists but prospective sellers do not respond. In the housing market, a seller first pays a sunk entry cost - the up-front cost of moving, preparing, or building the home. If entry were to occur, the monopolistic bidder would not compensate the seller for this sunk cost. Due to this hold-up problem, the outcome during this dormant period is therefore inefficient.

This pattern of trade (and its associated inefficiency) also varies with the cost of entry and with the desire to own a home. The duration of cold spells increases and a buyer's welfare during these cold spells falls as entry costs rise. On the other hand, as home ownership becomes more desired, cold spells shorten resulting in higher welfare when such cold spells occur.

Simulations reveal that the model can generate cold spells that substantially alter standard measures of the housing market performance. With forgone entry lasting as long as three months, the model performs well when viewed along side the housing market of Dane County, Wisconsin home of the city of Madison. The model without these spells of withheld entry does not perform nearly as well. The implications of hot and cold spells - persistence in price, variation in sales, and correlation of price with sales - are prominent in simulations of the model. Simulated outcomes also exhibit high variation in time on the market, correlation of time on the market with price and correlation with price and lagged inventory. These outcomes are either much smaller or not present in the model with fixed exogenous entry and hence without cold spells.

There is also a more direct link between the model and the data when the observations are decomposed into finer segments. In Madison, small, distinct housing markets exhibit frequent spells with zero sales and with a high number of sales. Models without explicit fluctuations are inconsistent with this finding. On the other hand, simulations of this model with hot and cold spells replicate this finding.

The rest of the paper is as follows. The next section reviews the literature which provides context for the model and the results. The third section presents a baseline version of the stock-flow matching model and specifies the nature of hot and cold trading spells. The following section defines and establishes existence (as well as uniqueness) of an equilibrium, explores its welfare properties, and reports comparative statics. Section 5 examines the implications of the underlying trading assumptions. Section 6 then presents simulated market outcomes for an 
enhanced version of the model. These outcomes along with similar measures from the model without an entry decision (and hence without hot and cold spells) are then compared with observations from Dane County. Section 7 concludes.

\section{Related Literature}

This paper develops a dynamic equilibrium model of the housing market based on stock-flow matching. The stock-flow microstructure outlined above expands on random bilateral matching and by construction incorporates competitive Bertrand bidding (i.e. auctions) from the long side of the market. This paper demonstrates that if sellers in this framework exercise control over their market entry, endogenous hot and cold cycles that increase market volatility emerge. Thus, the paper contributes to the literature on the microstructure and trading dynamics of housing markets as well as to the wider literature on search markets involving both auctions and bargaining.

Dating at least as far back as Wheaton (1990), the application of search frictions to housing markets addresses three broad empirical regularities.

- Housing cycles occur - there is short run positive serial correlation in prices but mean reversion in the long run (Case and Shiller, 1989; Muelbauer and Murphy, 1997).

- There is excess volatility in prices and quantities relative to fundamentals (Shiller, 1982; Glaeser et al, 2014).

- Price and sales exhibit positive correlation, while price and seller time-on-market (i.e. liquidity) exhibit negative correlation (Stein, 1995; Krainer, 2001; Glaeser et al, 2014).

Han and Strange (2015) review recent search and matching models of the real estate market and observe that while the basic pairwise random matching model can generate some of these stylized facts in response to external shocks, it struggles to fully explain both persistence and excess price volatility, even when the model allows for a variety of amplification mechanisms. This paper addresses the above empirical regularities without appealing to external variation in trading conditions and hence supplements potential rationales behind these dynamic observations.

Han and Strange also note that our understanding of the mechanics of housing auctions in dynamic settings with search frictions - the approach adopted in this paper - is very limited. Although bidding wars are common in practice, price determination in most matching models with frictions derives from one-to-one bargaining. See also Arefeva (2017).

The contribution here addresses this methodological deficiency and allows the negotiated price to account more fully for direct competition among buyers. Caplin and Leahy (2011) and Arefeva (2017) take similar aim. This paper complements their contributions. Arefeva allows for multiple buyers to match with and bid for a house in a given period and shows the importance of possible bidding wars in amplifying the observed house price volatility. ${ }^{1}$ She demonstrates that

\footnotetext{
${ }^{1}$ Albrecht et al (2016) build a static auction model with directed search to study the role of the asking price in the housing market.
} 
both the prevalent dynamic random and directed search models with bargained prices cannot explain price volatility. Incorporating auctions substantially increases volatility. Arefeva's analysis, however, concentrates on price volatility resulting from the propagation and amplification of external shocks. This paper assumes constant gains to trade and focuses on endogenous boom and bust cycles. It also broadens the empirical outlook by exploring not only price volatility but also the other measures of variability outlined above.

Caplin and Leahy (2011) also use Bertrand competitive bidding across segmented housing markets. Their structure shares several features with this paper, excludes exogenous sources of price fluctuations, and considers the broader set of empirical regularities outlined above. Caplin and Leahy, however, do not allow for a seller entry margin. ${ }^{2}$ As a result, trading cycles are absent and their paper admits to "mixed success" in replicating the stylized facts. Fluctuations in Caplin and Leahy are, for example, short lived. The entry decision appears critical which is consistent with recent findings showing the supply side to be an important determinant of volatility of house prices. ${ }^{3}$

Arefeva's (2017) focus on amplifying shocks associated with the business cycle to address excess volatility follows the approach found in much of the search and matching housing literature on trading volatility and co-movements. These papers tie booms and busts in the housing market to macroeconomic volatility. Krainer (2001) specifies aggregate demand shocks and demonstrates a positive correlation in prices, sales and liquidity. House price volatility in Krainer (2001), however, is lower than aggregate volatility - changes in liquidity (time to sell) respond as well to aggregate shocks and absorb some of the market-wide variation. Novy-Marx (2009) obtains amplification and generates excess volatility through an endogenous market tightness response to aggregate demand shocks. Increased demand for houses (say from rising incomes) enables sellers to trade faster. Fewer houses are thereby available next period which then leads to a further price rise and amplification of the shock. A limited supply side response generates a market tightness feedback mechanism that amplifies demand shocks while maintaining co-movement in prices, sales and selling probabilities across steady states. Diaz and Jerez (2013) add aggregate supply shocks to the Novy-Marx insight and quantify the feedback mechanisms. They find that amplification and propagation are more pronounced in a competitive search environment than under random search. Head et al (2014) likewise calibrate a directed search model to explore the dynamics of house prices, sales, construction, and the entry of buyers in response to cityspecific income shocks. Their model, which incorporates Wheaton's (1990) insight of the joint buyer-seller problem, quantitatively accounts for a large share of house price variation driven by income shocks and approximately half the serial correlation in house price growth. Ngai and Sheedy (2015) likewise emphasize the importance of the moving decision - to simultaneously sell the current house and buy a new one - in propagating and amplifying external shocks.

\footnotetext{
${ }^{2}$ Market history also differentiates the results. In Caplin and Leahy unsatisfied buyers (from the long side) randomly reallocate each period whereas here buyers and sellers are tied to their market segment. See Section 6 for further comparisons.

${ }^{3}$ See Glaeser et al (2008) and Saiz (2010). Anenberg and Bayer (2013) along with Ngai and Sheedy (2015) emphasize the importance of selling in the context of a joint buying and selling decision in housing search models. In contrast, Burnside et al (2016) and Landvoigt et al (2015) explore the importance of buyer entry for understanding booms and busts.
} 
Anenberg and Bayer (2013) takes a different approach to the joint decision and, like Caplin and Leahy (2011), is an exception to the amplification approach for explaining volatility. Anenberg and Bayer estimate a model in which the decision of homeowners to jointly sell their existing house and buy a new one creates a coordination externality that leads to an alternative explanation for endogenous booms and busts. ${ }^{4}$

Such analyses of endogenous cycles address the same empirical regularities that motivate the external amplification approach but are not intended to suggest that a given mechanism is the primary cause of any specific housing market cycle, including the boom and bust of the 2000's in the US. The objective instead is to identify the potential role of a mechanism in amplifying volatility across housing booms and busts, regardless of their root cause.

\section{Baseline Economy}

Buyers and sellers populate a small, specialized, isolated market for an indivisible good - a house or home - in continuous time. Buyers and sellers are risk neutral and discount at rate $r>0$. At the start of time the market is empty. As time proceeds, buyers looking for a home enter the market at the constant, exogenous Poisson rate $\beta>0$. Sellers each with one home for sale obtain the option to enter the market at the exogenous Poisson rate $\sigma>\beta$. Both buyers and sellers are drawn from countably infinite populations so that given the Poisson arrival processes at most only one agent enters the market at a point in time.

Sellers can choose whether to take advantage of their entry opportunity or to decline entry. For example, a home owner might contemplate trading but if the perceived current conditions are unfavorable, their situation allows them to hold off and stay where they are. Potential sellers thus receive the opportunity to participate in the market more frequently than buyers but realized seller entry is endogenous. ${ }^{5}$

A buyer derives $x$ units of discounted total lifetime utility from home ownership. For sellers, the flow utility from ownership is normalized to zero. Moreover, sellers do not have the option to wait or return at some other time. As a result, the payoff to a seller who decides to turn down the trading opportunity and declines to participate in the market is zero.

A seller who receives an opportunity to trade and is considering whether to enter the market knows the outcome of the previous auction, including the number of bidders and the date of that auction. A potential new seller also knows whether there are any existing homes for sale, that is if there are any unsatisfied prior sellers who entered the market but did not trade. This seller, however, does not know the outcome of buyer entry over the period since the last auction was held. Since buyers enter at Poisson rate $\beta$, sellers and buyers share the belief that the

\footnotetext{
${ }^{4}$ Ngai and Tenreyro (2014) also exhibits cyclical variation that complements the mechanism proposed here. In contrast, the standard DMP model with free entry has a unique steady state with constant expected flow of trade.

${ }^{5}$ The standard specification in the stock-flow literature is that buyer and seller entry are equal and exogenous so that market balances over time. Persistent unequal entry would eventually lead towards an infinity of buyers or sellers.
} 
probability of $i$ entrants over a duration $D$ since the last auction is given by

$$
\pi_{i}(D)=\frac{e^{-\beta D}(\beta D)^{i}}{i !}
$$

Sellers who accept an opportunity to enter the market pay an up-front fixed cost of entry $F>0$ so the potential gains from trade between a potential seller and an existing buyer are $x-F>0$. If entry occurs, the seller immediately holds a full information, first price auction for their good in a second stage of the entry period. The calling of an auction reveals to all agents the total number of bidders before they submit their offers. All participants are revealed and all buyers in the market are obliged to bid. As agents in the market are perfectly informed about existing trading conditions, there are no impediments to trade after entry.

In the third and final stage at the entry date, sellers either accept a single bid or reject them all. A sale therefore might not occur either because the seller rejected all bids or because there are no bidders currently in the market. If an auction is held and a sale does not take place for whatever reason at date $t$, the house remains active in the market. The seller is compelled to hold another auction in the next instant at $t+d t$ for vanishing duration $d t$. A buyer who enters when there are no other buyers present is thus aware of all available houses for sale. Multiple auctions could take place simultaneously if sellers continuously rejected buyer bids or if sellers choose to enter markets with existing sellers.

If a trade takes place, the consummating buyer and seller both permanently leave the market. An accepted bid at price $P$ yields a payoff $x-P$ to the buyer and transfers revenue $P$ to the seller. Unsatisfied buyers and sellers remain behind to wait for the next trading opportunity. Idle agents waiting for a possible trade receive and make no payments but do not leave the market.

\subsection{Market States and Transitions}

In a closely related environment with exogenous (and equal) entry, Coles and Muthoo (1998) establish that in any Markov perfect equilibrium, trade takes place immediately whenever gains to trade exist. (See also Taylor, 1995.) To see this result, suppose that up to some point in time all past entrants have exhausted all possible trading opportunities so that there are either excess buyers or excess sellers but not both. Now suppose seller entry occurs when there is more than one excess buyer. Without impediments to trade, buyers on the long side of the market compete with each other and bid up to their reservation value at which point they are indifferent between purchasing and waiting. If a trading surplus exists, the buyers' bids exceed the seller's reservation payoff. The seller selects the highest bid, or more generally selects randomly among the set of identical, highest bids from the indifferent buyers. On the other hand, let there be excess sellers in the market and suppose a buyer enters the market. This buyer is on the short side of the market and hence the lone buyer. As such the buyer will bid the reservation value of the seller or sellers who are willing to accept the offer. The buyer then selects randomly among the houses for sale.

Similar logic applies here. To keep the analysis tractable and focus on entry decisions, this 
paper imposes immediate trade. In particular, the paper adopts this stage game outcome when a buyer or seller joins the market. The analysis then characterizes payoffs consistent with this behaviour and establishes that delay is costly so traders would not want to deviate in equilibrium. The paper does not consider more complex, history dependent trading strategies which may lead to delayed trade in equilibrium. See Coles and Muthoo (1998) for a further discussion.

Assertion A1: Immediate trade occurs so that the market never simultaneously has unsatisfied buyers and unsatisfied sellers.

Agents realize the gains to trade in the market without delay. Sellers formulate a reservation price. At least one buyer's bid exceeds this value in order to carry out trade. The seller accepts the best bid so that in equilibrium sellers do not reject all offers.

In an immediate trade equilibrium with fully revealing auctions, the state of the market can be summarized by an integer, $N$, denoting the known participants remaining from the last sale and a duration $D \geq 0$ denoting the time since the last seller entry and auction. In particular, if over the course of market history up to the time of the last sale, a total of $N_{B}$ buyers and $N_{S}$ sellers had entered, then

$$
N=N_{B}-N_{S}
$$

represents the number of known buyers (sellers) remaining after a sale for $N>0(N<0)$.

Given a vanishing interval length $d t \rightarrow 0$ and buyer entry $i \in \mathbb{N}$ since the previous auction, state transitions follow

$$
\begin{array}{rlr}
\Gamma(N, D) & =(N, D+d t) \mid \text { No Seller Entry } \\
& =\left(N^{\prime}, 0\right) \quad \mid \text { Seller Entry } \\
& =\left(N^{\prime}, d t\right) \quad \mid \text { Seller Acceptance or Rejection }
\end{array}
$$

where $N^{\prime}=N+i-1 .^{6}$ If seller entry does not take place, the state, $D$ in particular, evolves incrementally with time whereas $N$ remains unaltered as buyer entry $i$ remains obscured. If seller entry occurs, the duration is reset to $D=0$ and $N$ is updated before the bidding phase to include not only revealed buyer entry $i$ but also the seller's own entry. After the auction concludes, the duration measure moves along in step with time. As such, $D=0$ indicates an auction is taking place.

With no delays in trade, periods between observed sales result from waiting times between seller entry when there are excess buyers, or between buyer arrivals if there are excess sellers. When sellers turn down entry opportunities, these waiting times become prolonged. Let the entry decision therefore define hot and cold states.

Definition: A state is hot or active when sellers accept the option to enter, and is cold or dormant when potential sellers decide not to participate.

To identify hot and cold states, suppose that the transaction price falls as the number of bidders declines so that the market becomes less profitable for sellers with fewer bidders. Since

\footnotetext{
${ }^{6}$ To keep the state moving along, rejection implicitly involves (re-)entry in the next instant from the same seller.
} 
the number of bidders is known with certainty immediately following an auction, potential sellers will decline entry (given a sufficiently high $F$ ) for some period of time after an auction that leaves the number of remaining buyers below a zero expected profit threshold which reflects the competitiveness of bidding.

The distinction in market power between one and two bidders plausibly determines the threshold state for entry. Monopolistic bidding allows the buyer to capture the trading surplus. ${ }^{7}$ If a monopolistic buyer can take advantage of the lack of competition and offers a bid (at or above the reservation sale price but) below the sunk fixed entry cost, $F$, potential sellers will decline the opportunity to participate immediately after auctions with zero or one bidder remaining. In contrast, two or more Bertrand competitors are on the short side of their market thus market power resides with the seller. Competitive bidding from two or more buyers, creates a different scenario that can induce competing bidders to offer a profitable price.

The candidate outcome put forward is that sellers enter in any state with two or more known available bidders but entry ceases for some period of time following an auction with one remaining buyer who bids monopolistically not competitively.

Assertion A2: (Monopoly - Bertrand Partition) The market is hot for all states where $N \geq 2$. For $N=1$ and $D=d t$ the market is cold.

This assertion implies that the market becomes cold immediately following an auction with two bidders. Although this specification eases the exposition, conditions on entry fee levels that deliver this assumed threshold will be derived below.

To make entry profitable and revitalize seller entry so that cold states become hot, buyer entry must replenish the pool of bidders. Immediately after an auction, the number of potential bidders is known with certainty. As time proceeds, random buyer entry occurs. If no houses are or become available, no auctions occur and potential sellers do not observe buyer entry. As time proceeds without trade, the number of potential buyers grows stochastically. Expected prices rise. For markets with zero or one known buyer, trade in the market eventually becomes profitable, seller entry resumes and the market becomes hot. The selling process coupled with Assertion A2 implies that cold markets transition to a hot market only from states with $N \in$ $\{0,1\}$ after endogenous durations $D=T_{1}$ and $D=T_{0}$ respectively.

The transition from cold to hot states does not occur for $N \leq-1$ so that in this benchmark economy there is never more than one seller in the market at all dates. Consider the following sequence of events. After a sufficient duration from the time of an auction with only one bidder, suppose no buyers have entered and seller entry gets switched on. If a seller then enters before a buyer, there are excess sellers $(N=-1)$. The unsuccessful seller is the only agent currently in the market so no sale takes place. As potential entrants observe an existing seller already in the market and the absence of any sale with excess sellers, they will turn down entry until the existing house is sold. Trade eventually takes place when a buyer arrives in which case the market transits to $N=0$ and $D=d t$. After such a sale, the market is empty with no houses

\footnotetext{
${ }^{7}$ The previous auction may have any non-negative number of left over bidders - zero, one, or more. If the previous auction left zero bidders remaining, the next buyer to enter would obtain monopoly status, at least for some period of time.
} 
for sale and no bidders wanting to buy. Thus, immediately after that trade, entrants continue to decline trading opportunities until after a further duration $T_{0}$. Hence, A2 implies the set of hot states is given by

$$
\Omega=\left\{(N \geq 2, D \geq 0) \cup\left(N=1, D \geq T_{1}\right) \cup\left(N=0, D \geq T_{0}\right)\right\}
$$

All other states are cold.

\subsection{Payoffs}

In state $(N \geq 0, D=0)$, an auction takes place with one house for sale and $N+1$ buyers bidding. For example, in the instant before the seller entered, suppose there were four buyers known from the previous sale waiting for a home to arrive along with two new buyers unknown to the seller, $i=2$. The old state was $N=4$. Entry revealed these six buyers and set the duration to $D=0$. At the auction stage of events, the just updated state $N$ is defined as total buyers less total sellers which is five including the one seller that just entered. After a successful auction, the market will have $N=5$ known buyers going forward as time proceeds.

Let $P(N)>0$ denote the buyers' symmetric price bids in this auction. Let seller rejection of $P(N)$ yield $Z(N)$ whereas the seller's payoff from acceptance is simply the price offered. Let $H(N)$ represent the payoff to a house buyer from being in a hot, active market with $N \geq 1$ bidders (including the buyer) waiting for the arrival of a seller. As buyers are passive between auctions, their bids and hence hot market payoffs are contingent on only the newly updated $N$ and not $D$ which always equals zero in an auction. These bids and payoffs, however, account for the expected actions of the other participants in the current stage as well as the expected duration until and events in future auctions.

Let $C(T ; N, D)$ represent the expected payoff to a buyer in a cold market who must wait the remaining duration $T>0$ before sellers with the option of entry become willing to pay $F$ to visit the market, i.e., before the market becomes hot again and the entry of sellers resumes. In general, the expected payoff in a cold market is given by

$$
C(T ; N, D)=e^{-r T} \sum_{i=0}^{\infty} \pi_{i}(D+T) H(N+i)
$$

where again $\pi_{i}(t)$ denotes the probability that $i$ buyers entered the market after a duration $t$ in which case $N+1$ bidders await an incoming seller. By Assertion A2, however, a market with more than one known buyer $N>1$ is active whereas buyers are absent (at least initially) for $N \leq 0$. The only relevant cold market payoff for characterizing trade therefore occurs at $N=1$.

After a seller accepts a bid in an auction with two buyers, one buyer remains in the market and the market becomes cold. The buyer who does not purchase the house receives expected payoff $C\left(T_{1} ; N=1, D=0\right)$ where $T_{1}$ denotes the duration that this seller must wait after the sale before seller entry resumes. For all $D \geq T_{1}$, the state $(N=1, D)$ is hot. $^{8}$

\footnotetext{
${ }^{8}$ The duration of a cold spell depends on the number $N$ of excess buyers remaining from the last trade or seller entrance (if no trade occurred) hence the subscript notation with $N=1$. From the buyers perspective, the
} 
Before entry occurs, the seller's revenue is uncertain since unobserved buyer entry can occur between trades. If $N \geq 1$, a potential house seller knows a sale will occur immediately - there is at least one buyer in the market - but not the transaction price. Following a spell of duration $D>0$ without seller entry, expected revenue less the entry fee for a seller contemplating entry into the market is given by

$$
R(N, D)=\sum_{i=0}^{\infty} \pi_{i}(D) P(N+i-1)-F
$$

If $i \geq 0$ buyers arrived during $D$ to replenish the market, the anticipated price $P(N+i-1)$ accounts for both $i$ revealed buyers and the seller's own entry.

Without a known existing buyer, $N=0$, there is the possibility of a seller not finding a buyer in the market. If no buyers remain from the last auction and none have entered after some duration $D$, an entering seller would have to wait for a buyer to enter. During this wait, $N=-1$ and no other seller will enter. When a buyer does show, the state becomes $(0,0)$ and the buyer bids a price $P(0)$ that makes the existing seller indifferent between accepting and rejecting. Given the rate of buyer entry, the discounted expected payoff to a seller alone in the market (in effect rejection through no bidding) is

$$
Z(-1)=\frac{1}{1+r d t}[\beta d t P(0)+(1-\beta d t) Z(-1)]
$$

so that

$$
Z(-1)=\beta P(0) /(r+\beta)
$$

If one buyer arrived since the last auction, it is also a lone bidder again bidding $P(0)$ but in this case the transaction takes place immediately. Likewise for two or more bidders with the number of bidders all coming from new buyers. Accounting for the probabilities of bidder numbers as well as the impact of seller entry on the price, expected revenue less costs is given by

$$
R(0, D)=\pi_{0}(D) Z(-1)+\sum_{i=1}^{\infty} \pi_{i}(D) P(i-1)-F
$$

For $N \leq-1$ as discussed above, sellers do not enter until the existing house sells - expected revenue $R(-1, D)$ to further seller entry is negative.

\subsection{Price Offers and Seller Entry}

To solve the auction stages recursively, note that the seller's acceptance payoff is strictly increasing in price. Hence, the seller's best response strategy in an auction has the reservation property. In state $(N, 0)$, the seller accepts $P(N)$ if and only if $P(N) \geq Z(N)$.

Now consider the bidding phase and suppose first that $N=1$ and $D \geq T_{1}$, so that the market has become hot after a cold spell. If a seller enters and no buyer entry had occurred during the cold spell, $N$ shifts and the ensuing auction proceeds with $N=0$. With one bidder market is hot if $N \geq 2$ and non-existent for $N \leq 0$ making $C\left(T_{1}\right)$ payoff relevant to the buyer. 
making an offer for the one house for sale, the well known Diamond result holds. The buyer optimally bids the seller's reservation price, $P(0)=Z(0){ }^{9}$

With two or more bidders $(N \geq 1)$ price offers are derived from the hot and cold market payoffs $H(N)$ and $C\left(T_{1}\right)$ where to ease notation the understood state $N=1, D=0$ in $C\left(T_{1}\right)$ is now dropped. Following Taylor (1995) for $N \geq 1$, the buyers become indifferent between paying $P(N)$ and waiting for the next seller to enter, whether in a cold market for $P(1)$ or in hot market for $P(N)$ with $N \geq 2$.

These monopolistic and competitive bidding scenarios yield the following characterization of prices offers.

Lemma 1: Price offers are given by :

$$
\begin{gathered}
P(0)=Z(0)=\frac{\beta}{r+\beta} P(1) \\
P(1)=x-C\left(T_{1}\right) \\
P(N)=x-H(N) \quad N \geq 2
\end{gathered}
$$

Proof See Appendix.

Provided that sellers accept the buyers' bids, i.e. $P(N) \geq Z(N)$ for all $N \geq 0$, these prices coupled with the cold state payoff $C\left(T_{1}\right)$ in turn determine bidder payoffs $H(N)$ in a hot market. For $N=1$ and $D>0$, the buyer is alone in the market waiting for the arrival of a seller who will accept entry, a situation that arises after the transition from a cold period without buyer entry. Two such transitions occur. One transition occurs after a duration $D>T_{1}$ following a two bidder auction during which no buyer entry occurred. The second occurs after duration $D>T_{0}$ that follows an auction with one bidder during which no buyer entry occurred.

Accounting for these transitions along with the entry rate of traders characterizes the buyer payoffs in hot markets.

Lemma 2: The payoffs in the hot markets are given by

$$
\begin{gathered}
H(1)=\frac{\beta H(2)+\sigma(x-P(0))}{r+\sigma+\beta} \\
H(2)=\frac{\sigma C\left(T_{1}\right)}{r+\sigma+\beta(1-\eta)} \\
H(N)=\eta^{N-2} H(2) \quad N \geq 3
\end{gathered}
$$

where

\footnotetext{
${ }^{9}$ The $N=0$ price bid could be specified in a number ways with offer/counter-offer bargaining as a leading alternative. The details will change but the basic mechanism does not hinge on the way in which agents divide this surplus. Alternative outcomes that share the trading surplus have little impact on the existence of hot and cold spells.
} 


$$
\eta=\frac{r+\sigma+\beta-\left[(r+\sigma+\beta)^{2}-4 \sigma \beta\right]^{1 / 2}}{2 \beta}
$$

Proof See Appendix.

Note that $H(N)$ is decreasing in $N$ so that prices along with expected revenue $R(N, D)$ decline with the number of bidders as proposed above.

The derivation above of the monopolistic price $P(0)=Z(0)$ implies that the seller accepts this bid. To establish that the other $P(N)$ bids also (weakly) exceed the seller's option of waiting, that is the reservation value for trade $Z(N)$, assume that if another seller enters the market, then this new seller immediately carries out its business and departs with a sale. The existing first seller who delayed can then act.

The seller's option of delay in this protocol is less than the offered price for all $N \geq 1$ so that the seller accepts a buyer's bid $P(N)$.

Lemma 3: In all states $N \geq 1$, the seller's payoff to waiting

$$
Z(N)=\frac{1}{1+r d t}[\beta d t P(N+1)+\sigma d t P(N-1)+(1-\beta d t-\sigma d t) P(N)]
$$

exceeds the price offer $P(N)$.

Proof See Appendix.

Now consider a potential seller contemplating the market in the entry phase. This seller's decision depends on whether the expected revenue $R(N, D)$ outweighs the cost of entry. If the expected revenue following seller entry is less than the up-front fee $F$, sellers decline entry. They accept otherwise.

From the monopoly-Bertrand partition assertion A2, sellers accept entry opportunities and markets are hot for all states in which $N \geq 2$. Moreover, sellers decline entry and markets are cold for $N=-1$. When $N \in\{0,1\}$, sellers turn down entry over some period of time after a sale. For $N=1$ entry resumes after a period $T_{1}$. Sellers turn down entry in states $\left(N=1, D<T_{1}\right)$ but the market becomes hot at $\left(N=1, D=T_{1}\right)$ and remains hot for all $D \geq T_{1}$. For $N=0$ and $D=d t \rightarrow 0, T_{0}$ denotes the duration of the subsequent cold spell.

Expected net revenues or profit determine the corresponding durations $T_{1}$ and $T_{0}$. Suppose first that there is one remaining buyer from the last auction, $N=1$. If no new buyers have entered since the previous auction $(i=0)$, seller entry decreases $N$ and the lone buyer bids the price $P(0)$. With two bidders (one old and one new), the seller receives $P(1)=x-C\left(T_{1}\right)$ where the unsuccessful buyer expects sellers to delay entry for the period of duration $T_{1}$. With three or more bidders $(i \geq 2)$, the price offered and paid is $P(i)=x-H(i)$. Plugging in these outcomes along with the Poisson probabilities $\pi_{i}(t)$, expected profit becomes

$$
R(1, D)=e^{-\beta D} P(0)+\beta D e^{-\beta D}\left[x-C\left(T_{1}\right)\right]+\sum_{i=2}^{\infty} \frac{(\beta D)^{i} e^{-\beta D}}{i !}[x-H(i)]-F
$$

Entry occurs if and only if $R(1, D) \geq 0$. 
When there are no buyers remaining from the last auction $(N=0)$, entry occurs if and only if the corresponding cold spell duration $T_{0}$ is sufficiently long so that $R(0, D) \geq 0$. Plugging in again for prices $P(N)$ as well as for $Z(-1)$ delivers the following result.

Lemma 4: For sellers aware of only one or zero known bidders, the critical cold spell duration of delayed entry $T_{1}$ and $T_{0}$ respectively solve

$$
\begin{aligned}
R\left(1, T_{1}\right)= & e^{-\beta T_{1}} P(0)+\beta T_{1} e^{-\beta T_{1}}\left[x-C\left(T_{1}\right)\right] \\
& +\sum_{i=2}^{\infty} \frac{\left(\beta T_{1}\right)^{i} e^{-\beta T_{1}}}{i !}[x-H(i)]-F=0
\end{aligned}
$$

and

$$
\begin{aligned}
& R\left(0, T_{0}\right)=e^{-\beta T_{0}} \frac{\beta P(0)}{r+\beta}+\beta T_{0} e^{-\beta T_{0}} P(0)+\frac{\beta T_{0}^{2}}{2} e^{-\beta T_{0}}\left(x-C\left(T_{1}\right)\right) \\
&+\sum_{i=3}^{\infty} \frac{\left(\beta T_{0}\right)^{i} e^{-\beta T_{0}}}{i !}[x-H(i)]-F=0
\end{aligned}
$$

The last step in this section is to verify that the monopoly-Bertrand partition in A2 is valid. Given prices, payoffs and cold spells from Lemmas (1)-(4), sellers would enter monopolistic $(N \leq 1)$ markets and the market would remain hot if discounted expected net revenue is positive immediately following an auction that left one bidder remaining in the market:

$$
R(1 ; d t)=P(0)-F=\frac{\beta}{r+\beta} P(1)-F=\frac{\beta}{r+\beta}[x-C(0)]-F>0 .
$$

Conversely, markets with two known remaining bidders would become cold and entry would not occur if the expected price did not cover fixed costs:

$$
P(1)=x-C\left(T_{1}\right) \leq F
$$

The proposed monopoly-Bertrand auction distinction in Assertion A2 that delivers the threshold requirement for entry therefore holds for

$$
\frac{\beta}{r+\beta}[x-C(0)] \leq F \leq x-C\left(T_{1}\right)
$$

The left hand side inequality of (4) can be expressed parametrically.

Lemma 5: If and only if

$$
F \geq F^{c} \equiv \frac{\beta[r(r+\sigma+\beta(1-\eta))+\beta(r+\beta(1-\eta))] x}{r(r+\sigma+\beta)(r+\sigma+\beta(1-\eta))+\beta(r+\beta)(r+\beta(1-\eta))}
$$

then

$$
\frac{\beta}{r+\beta}[x-C(0)] \leq F
$$


Proof See Appendix.

The right hand side for entry with two bidders, $F \leq x-C\left(T_{1}\right)$, contains an endogenous payoff $C\left(T_{1}\right)$; however, the proof of Proposition 1 in the appendix establishes the natural result that buyers prefer a zero duration cold spell, that is $C\left(T_{1}\right) \leq C(0)$. Therefore, a sufficient, lower bound condition for the right hand side to hold is $F \leq(r+\beta) F^{c} / \beta$. An upper bound can also be established. If $F \geq \beta x /(r+\beta)$, then the right hand side condition and hence A2 does not hold.

\section{Equilibrium}

Definition: An immediate trade, monopoly-Bertrand partitioned, Markov Perfect Bayesian Equilibrium with fully revealing auctions is set of state contingent

- rational expectations regarding buyer entry, $\pi_{i}(D)$

- state transitions $\Gamma(N, D)$

- seller reservation price thresholds, $Z(N)$

- buyer price offers $P(N)$

- seller waiting durations $T_{0}$ and $T_{1}$ such that sellers accept the option to enter only in states

$$
\Omega=\left\{(N \geq 2, D>0) \cup\left(N=1, D \geq T_{1}\right) \cup\left(N=0, D \geq T_{0}\right\}\right.
$$

as specified in Lemmas (1)-(4) and satisfying equations (1), (2), and (3).

Proposition 1: If the conditions for (4) hold, then there exists a unique, immediate trade, monopoly-Bertrand partitioned, Markov Perfect Bayesian Equilibrium.

Proof: See Appendix

In equilibrium with $T_{0}>T_{1}>0$, the model exhibits a recurrent pattern of hot and cold spells of trade. The mechanism underlying these hot and cold fluctuations is related to the cyclical processes of conventional $s-S$ models. Trade stochastically erodes hot housing markets with a stock of buyers present. These hot markets will eventually turn cold once seller entry (which is faster than buyer entry) runs down the stock of buyers and becomes no longer profitable. Unlike conventional $s-S$ models, the stock replenishes slowly as in Smith (2007). Entry resumes after a sufficient time elapses for expected turnover to revitalize the market.

Although trade occurs immediately following entry, the existence of hot and cold spells is inefficient due to a familiar hold up problem. With one buyer known to exist in the market $(N=1)$, a social planner would want entry. There are unexploited gains to trade. Declined entry by sellers during a $T_{1}$ cold spell is therefore suboptimal and attributed to the inability of sellers to recoup their sunk costs of entry.

When there are no known buyers in the market $(N=0)$, entry is again inefficient. If after duration $D$, a new buyer has not yet entered (with probability $\pi_{0}(D)$ ), then a seller who enters 
must wait. Since buyers arrive at rate $\beta$, the expected joint discounted payoff to trade in this situation is $\frac{\beta}{r+\beta} x$. In this case, the joint expected return to seller entry after duration $D$ is

$$
\sum_{i=1}^{\infty} \pi_{i}(D) x+\pi_{0}(D) \frac{\beta}{r+\beta} x-F
$$

Plugging in and simplifying reveals that this payoff is non-negative if and only if

$$
D \geq T_{0}^{P}=\frac{-\ln \left[\frac{r+\beta}{r}(1-F / x)\right]}{\beta}
$$

It is straightforward to see that

$$
R\left(0, T_{0}\right)<\sum_{i=1}^{\infty} \pi_{i}\left(T_{0}^{P}\right) x+\pi_{0}\left(T_{0}^{P}\right) \frac{\beta}{r+\beta} x-F .
$$

Since firm payoffs do not account for the benefits obtained from the buyer in their entry decision, firms again delay entry longer than is socially optimal when no one is in the market, i.e. $N=0$. The following result summarizes this discussion.

Proposition 2: Equilibrium is inefficient.

Equilibrium can be characterized further. The following comparative static result establishes the way in which trading delays and cold market payoffs vary with key parameters.

Proposition 3: An increase in seller costs increases the cold spell duration $T_{1}$ and decreases the cold state buyer payoff $C\left(T_{1}\right)$. An increase in the utility of home ownership $x$ decreases the cold spell duration $T_{1}$ and increases the cold state buyer payoff $C\left(T_{1}\right)$.

\section{Proof: See Appendix}

Given the stock-flow matching framework, these comparative static results are not surprising. As the gains to trade rise, agents become more eager to exploit these gains. On the other hand, they suggest that less valuable houses will exhibit greater fluctuations, a relationship that can potentially help interpret the the market dynamics and co-movements explored in the quantitative section below.

\section{Discussion}

In this paper, endogenous seller entry and stock-flow matching are critical for the existence of hot and cold cycles. Stock-flow matching stochastically generates time between exchange as the long side of the market waits for the arrival of traders on the short side. Allowing endogenous entry generates further delays exacerbating the time between observed trades. On occasion, some potential traders forgo the market which produces the cold trading spells.

So, how well suited is this particular matching framework for analyzing the housing market, its volatility, and co-movements? ${ }^{10}$ The stock-flow microstructure is simple and plausible with

\footnotetext{
${ }^{10}$ Han and Strange (2015) claim that "there is a strong case for considering models with robust microfounda-
} 
empirical validity coming from labor market studies. ${ }^{11}$ This approach has featured prominently in several recent papers on job and worker flows. ${ }^{12}$ In addition, the stock-flow microstructure embeds several compelling features associated with the housing market. For example, in practice sellers hope for auctions but an auction is not guaranteed. The seller does not choose between an auction and a sequential decision process. The market decides. With stock-flow matching, the distinction comes from the joint evolution and possible swapping of the long and the short side positions in the market. Stock-flow matching thus provides not only a coherent setting for the existence of competitive bidding but also integrates a mechanism for the market to generate some houses being sold in bidding wars and others in a slower search-like fashion. ${ }^{13}$

Stock-flow matching also inherently involves thin markets in which a slowly evolving history matters. Unlike the urn-ball matching set-up in Arefeva (2017) and in Caplin and Leahy (2011), buyers and sellers in the stock-flow approach do not and cannot change circumstances rapidly period to period. It takes a while for the long side to evolve. This feature seems plausible for the housing market. Piazzesi et al (2017) find that buyers look in narrow market segments within metropolitan areas. Han and Strange (2015) also note the relevance of thin markets in housing.

On the other hand, to deliver and characterize hot and cold spells, the model is explicitly parsimonious. This simplicity highlights the critical components but abstracts from salient and quantitatively important elements of housing markets, many of which might not fit easily in with the stock-flow framework. ${ }^{14}$ Section 2 notes that business cycle fluctuations and the joint buyer-seller decision are absent here. Moreover, some features of the parsimonious stock-flow framework itself merit review.

As in conventional labor market search models (Pissarides, Chapter 1, 2000), the entry decision is on only one side of the market, hence an asymmetry exists between endogenous seller and exogenous buyer entry. ${ }^{15}$ To make this economy well behaved, sellers must appear more often - hence the specification that $\sigma>\beta$. As $\sigma$ becomes large, the specification approximates the standard free entry condition. More generally, the underlying idea is that when excess buyers are present, sellers arrive faster than buyers whereas when excess buyers are present, the reverse

tions." They also state that "in many of these equilibrium models, a stationary framework has been the dominant theoretical paradigm. However, a non-stationary equilibrium model would be particularly useful for assessing the dynamics of the housing market, such as the overshooting phenomenon in the short run and the stickiness of asking price."

${ }^{11}$ Using employment spell data, Coles and Smith (1998) obtain compelling evidence in favor of this matching behavior. See also Gregg and Petrongolo (2005), Shimer (2007), Coles and Petrongolo (2008), Kuo and Smith (2009) and Andrews et al (2013).

${ }^{12}$ For example, see Ebrahamy and Shimer (2010) and Carrillo-Tudela and Visschers (2013).

${ }^{13}$ Papers usually compare auctions with sequential search. For example, Wang (1993), Arnold and Lippman (1995). See Arefeva (2017) footnote 9.

${ }^{14}$ For example, allowing for heterogeneity among buyers or sellers as found in many pairwise matching models such as Arefeva (2017) would require keeping track of the number of every type of trader, a burdensome computation. Likewise, borrowing constraints and credit frictions do not arise (Stein 1995; Genesove and Mayer 1997; Ortalo-Magne and Rady 2006; and Hedlund 2016). Real estate agents (e.g. see Hendel et al, 2009), construction delays (see Davis and Heathcote, 2008; Gyourko and Saiz, 2006; and Head et al, 2014), rental housing markets (Halket and di Custoza, 2015), idiosyncratic and potentially privately known house characteristics (Haurin, 1988), increasing returns to matching (Ngai and Tenreyro, 2014) are similarly omitted.

${ }^{15}$ Endogenizing buyer entry might be realistic and possibly feasible but it is unnecessary to illustrate cyclicality. Endogenous buyer entry would complicate the model and raise a number of issues about renting and the link between buying and selling a home simultaneously. 
occurs.

The baseline framework further specifies that sellers do not observe buyer entry, reflecting in part that in real estate markets, sellers listing homes for sale tend to be serious whereas buyers who view houses are serious only if they are prepared to make an acceptable offer. This information structure can be attributed to the asymmetry in entry. The information revealed about previously called auctions can be known to all incoming traders; however, sellers can act upon what occurred in the market through entry, but buyers cannot. A seller calling an auction reveals the as yet unobserved buyer entry in the economy. Price reveals the number of excess bidders remaining. If a seller entered, initiated an auction and no transaction took place, all traders can infer that an excess seller exists until a buyer arrives and engages in the auction alone. Given the entry process, incoming buyers are unable to meaningfully respond to this information.

On the other hand, the information structure does amplify the variability of the hot-cold transitions. If sellers knew the number of buyers, the outcome would be more straightforward house sellers would never encounter a monopoly buyer. Two or more buyers would still attract seller entry so that any built up stock of buyers would erode until one buyer remained. The subsequent cold spell would then only last until a new buyer entered and became known thereby restoring the entry threshold of two buyers. If seller entry were high $(\sigma>>\beta)$ the stock of buyers would become small and cyclical trading less pronounced.

Another trading assumption is that sellers who pass on an entry opportunity do not wait in the market for conditions to improve. Potential sellers do not hang around. They look at recent prices and decide if it is a good time to sell. If recent prices are high, they put their house on the market or they begin construction. If prices are low, they turn their attention elsewhere. If all sellers remained in the market, the stock of these sellers would build up unsustainably over time. The lack of seller return approximates a situation in which households who wait for more favorable conditions do not return for a substantial period during which the market will have changed fundamentally and have little resemblance to current conditions. ${ }^{16}$ The long wait might be linked with schooling, family, employment or other commitments.

Perhaps more fundamentally, there are no movements across markets. In practice, although house sellers tend to be immobile across markets and might not differ substantially in how much they like the sales price, buyers who find stiff competition for a particular type of house in a confined neighborhood might expand their horizons. Likewise, in a narrow specific market as envisioned here, not all buyers will like the same house.

Including these or other features could improve the performance of the model but would complicate decision making and muddle the exposition. Moreover, it is not apparent how these or other features would eliminate the basic logic for hot and cold spells proposed here. For example, suppose buyers had idiosyncratic and heterogeneous house preferences that are unobserved by the seller until bidding occurs. Provided recent prices for similar houses revealed some information about the expected number of buyer types, sellers would formulate a threshold for profitable entry leading to hot and cold spells.

\footnotetext{
${ }^{16}$ Under a more general specification with search costs, sellers could decide when to return as in Smith (2007).
} 


\section{Quantitative Assessment}

The stylized features of the model highlight its essential mechanics but limit its quantitative performance. To boost the model's empirical capabilities, this section introduces modest extensions that enable more fitting comparisons of the simulated model not only with the model without endogenous entry (and hence without hot and cold spells) but also against familiar and commonly considered housing statistics from a mid-sized local US housing market - Dane County, Wisconsin. Dane County (pop 436,526 in 2000) is the home of the city of Madison which contains approximately half the population of the county.

The objective is not to generate definitive empirical findings. Although the quantitative model is enhanced, the exercise none the less leaves out prominent margins that can cause hot and cold spells, provided they withstand these potential extensions, to become more or less pronounced and thereby alter the alignment of the model with data. Given the abstract framework, the simulations are designed as a demonstration that under viable parameterizations, the model can deliver non-trivial hot and cold spells that not only are absent in standard settings but also generate outcomes consistent with established and observed regularities in the data.

\section{Extensions}

In the model, the housing market is small and precise, a specification consistent with the findings of Piazzesi et al (2017). In most statistics, however, a geographic area will typically contain numerous such markets defined by neighborhood and housing type. As geographic based statistics are broader than the model, the quantitative approach adopted here replicates and aggregates the model across a number of small markets to match up against familiar housing statistics at a local level.

These small markets are self-contained. Buyers and sellers only trade within their assigned market. In each of these markets, however, two extensions are added. The appendix provides details. The first extension introduces flow costs of being in the market. In the model above, the cost of not trading is delay and hence determined by discounting at rate $r$. In everyday practice, unmatched traders are likely to incur more substantial costs. Moreover, buyers are likely to differ from sellers in these additional costs. To account for such differences, let buyers and sellers now also have flow costs $d_{b}$ and $d_{s}$ respectively while waiting in the market. ${ }^{17}$

Second, the enhanced model allows for some exogenous seller entry. To obtain (from time to time) a non-neglible stock of unsold houses in the market (rather than sporadically having the unrealistic limitation of at most one unsold house), let there be two potential types of sellers as in Albrecht et al (2007). A portion of house sellers are now motivated (not relaxed) sellers who (like buyers) do not have a choice about entering the market. Their particular circumstances compel them to offer their home for sale. These entrants help shape the pattern of entry, the duration of active and inactive spells, the volume of trade and prices paid. Moreover, as these

\footnotetext{
${ }^{17}$ When search costs are small, cold spells are essentially too short to accumulate enough potential buyers to trigger the observed within month sales dispersion. Sellers, either motivated or relaxed, enter quickly after slow periods so that large numbers of buyers for sustained high frequency sales volume rarely accumulate. Likewise, cold spells are over and potential entry revived too quickly to create enough months without a sale. As a result, the structure of the model leads to a high number of months with just one sale.
} 
motivated sellers list their homes for sale in markets without buyers, inventories of unsold homes can build up. $N$ can now be any negative as well as positive integer.

The other type of seller continues to be relaxed or discretionary. As above, these sellers have the option to evaluate their prospects and decide whether to enter the market. In particular, using the same notation, relaxed sellers receive the opportunity to participate in a given market at the rate $\sigma>0$. Motivated sellers enter at rate $\alpha \geq 0$. To keep the market well behaved, these rates satisfy $\alpha<\beta$ and $\alpha+\sigma>\beta$. Since motivated sellers are compelled to entered the market, it is immaterial whether they pay the sunk entry cost $F$ paid by relaxed sellers.

With both relaxed and motivated sellers in the market, the transition from a cold phase to a hot phase can now come about in one of two ways. As before, the cold phase may conclude after a sufficiently long period of (complete) market inactivity without any (motivated) seller entry. Again, after some length of time, seller expectations of (unobserved) buyer entry eventually improve enough to induce entry of relaxed sellers. In addition, during the cold phase, a motivated seller might enter and trigger an auction. The outcome of this auction reveals the number of buyers who have entered during the cold phase of the market and hence resets the entry decision of potential relaxed sellers. If the auction reveals a sufficient number of remaining bidders $(N \geq 2)$, entry of relaxed sellers becomes re-activated. If not, the waiting decision resets itself to the beginning of the cold phase conditional on the number of bidders. If seller entry occurred but no sale followed, the inventory of available homes builds up. In this case, the market remains cold - no relaxed seller entry - until the stock of available homes is sold and then followed by an appropriate cold period of duration $T_{0}$ to replenish buyers.

Entry of motivated sellers occurs during both active and inactive markets. Relaxed sellers will not enter markets with excess supply until all of the previous sellers who entered consummate trades. They observe all unsatisfied trade and hence do not enter if another seller already exists in the market. Motivated sellers, however, may enter to cause additional excess supply. Really cold markets, those with excess sellers, remain cold until balance is restored. Even though motivated sellers enter at a slower rate than buyers, from time to time the realization of the entry processes will be such that more motivated sellers than buyers enter and cold markets will experience having excess sellers. A non-negligible inventory of unsold homes can now build up. $\underline{\text { Data }}$

The South Central Wisconsin Multiple Listing Service (SCWMLS) provides monthly data on average prices, sales, new listings and end of month inventory of unsold homes in Dane County from January 1997 onwards. The SCWMLS also lists average time on the market for unsold inventory until December 2002. To bypass the upheaval of the 2008 recession, the sample considers these series until December 2007.

The picture emerging from the Dane County data is consistent with three findings emphasized in the literature that suggest hot and cold spells in home sales. The three familiar findings from Dane and elsewhere are that

- prices exhibit persistence

- sales are volatile 
- prices correlate with contemporaneous sales

These and selected other measures are given below. The appendix provides details.

In addition, the data underpinning the Dane County statistics can be used to produce observations more directly linked with hot and cold spells. Hendel et al (2009) and Ortalo-Magné (2011) use the raw data generating the Dane County series for the period 1998-2005 to assess the housing market in Madison. It is possible to inspect their data for January 1999-December 2005 for hot and cold spells and analyze the distribution of sales across precise markets in a given month.

Houses in this data set belong to an assigned so-called quality class. In each elementary school district, let a separate market exist for each quality class. Most of the observed homes sold belong to five quality classes. ${ }^{18}$ There are 29 identifiable elementary school districts. Adopting a quality class of home in an elementary school district approach as in Ortalo-Magné (2011), there are potentially 145 good sized markets. Some elementary districts do not have home sales with all five quality classes. Eliminating the quality class $\times$ elementary school markets with no sales leaves 139 different sized markets.

A memoryless Poisson matching process for sales over time (which occurs in a standard random search model such as the familiar Diamond-Mortensen-Pissarides framework) would not exhibit hot or cold spells but would generate a distribution of sales in which the mean equals the variance. Table 1 therefore reports the average and maximum number of sales for each month along with the standard deviation across markets. Unsurprisingly, June and July are the busiest months and January and February the slowest. ${ }^{19}$ Although the size of these markets varies across markets and with time, the high degree of variation in sales suggests hot and cold spells exist. A more explicit test derives from a negative binomial regression which nests the memoryless Poisson model. Given month, year, quality class and average market size controls, the specification test rejects the Poisson specification $\left(\chi^{2}=2617.02\right.$, Nobs $\left.=11,592,\right)$. The Poisson specification is also rejected using a variety of more homogeneous subsamples. Restricting attention to those markets within a quarter standard deviation of the median sales and looking at sales for June and July, the test statistic is $\chi^{2}=8.76$, with Nobs $=476$.

A simple graphic approach illustrates the same excessive variation. Using the same data, the top panel in Figure 1 plots the distribution of sales in June and July for markets within a quarter of a standard deviation of the median number of sales. A Poisson distribution with an average of one and a half sales (which is roughly similar to the Madison average) is plotted in the panel immediately below. This figure reveals an abundance of both no sales and of a high number of sales in the data. Stated simply, there appears to be too much variation for a market with random matching which does not experience hot and cold spells.

\footnotetext{
${ }^{18}$ There are nine quality classes in the Hendel et al (2009) data. The sample here drops the two highest - most expensive - and two lowest - smallest units - quality classes which are also the smallest groups. A small percentage of houses are classified in-between quality classes and also dropped from this analysis.

${ }^{19}$ Ngai and Tenreyro (2014) investigate this seasonality component.
} 
Table 1. Average Monthly Market Sales

\begin{tabular}{lccc}
\hline & Mean & Standard Deviation & Max \\
\cline { 2 - 4 } January & 0.7184 & 1.3223 & 13 \\
February & 0.8643 & 1.6600 & 17 \\
March & 1.1925 & 2.2200 & 31 \\
April & 1.4679 & 2.4086 & 25 \\
May & 1.8467 & 2.9276 & 25 \\
June & 2.2050 & 3.4234 & 32 \\
July & 2.1398 & 3.1754 & 28 \\
August & 1.8085 & 2.7672 & 21 \\
September & 1.2598 & 1.9817 & 16 \\
October & 1.1801 & 1.9652 & 19 \\
November & 0.9834 & 1.6350 & 14 \\
December & 1.0424 & 1.7641 & 13 \\
& & & 32 \\
Average & 1.3924 & 2.4067 & 3 \\
\hline
\end{tabular}

Source: Hendel et al (2009). Nobs $=966$

In a tentative first step toward relating the comparative statics from the model to observables, Table 2 reports the coefficient estimates of the quality class dummies from the negative binomial regression for the Nobs $=476$ restricted sample of markets with similar trading volumes. Although the coefficient estimates are insignificant, they and hence the coefficient of variation for sales of more desirable houses generally decreases. Cold spells interrupt active sales periods, so that markets with less pronounced inactive cold spells will have more consistent and sustained trading. The declining relative dispersion observed for more valuable homes thus appears consistent with the shorter cold spells associated with higher gains to trade shown in the model, i.e. with $d T_{1} / d x<0$. Table 2 also reports a rising $R^{2}$ from the hedonic price regressions (by quality class) used in Hendell et al (2009). Again, there appears to be less unexplained variation in prices for better houses which could be linked to shorter cold spells.

These connections, however, are preliminary. Among other limitations, the comparative static relates to the gains to trade between the buyer and seller which can differ from the price paid. None the less, when prices reflect the total gains to trade, a lower spread in sales and a price more closely tied to fundamentals would at first glance seem consistent with shorter cold spells causing less dispersion. 
Table 2: Quality Class Sales Estimates and Hedonic Price Regression $\mathbf{R}^{2}$

\begin{tabular}{ccc}
\hline Quality Class & Coeficient Estimate $(\mathrm{nbreg})$ & Hedonic Price Regression $\mathrm{R}^{2}$ \\
\hline 3 & 0 & $0.819(1755)$ \\
4 & $-0.072(0.138)$ & $0.885(5,234)$ \\
5 & $-0.183(0.136)$ & $0.887(4,458)$ \\
6 & $-0.194(0.127)$ & $0.933(3,293)$ \\
7 & $-0.039(0.161)$ & $0.910(925)$ \\
\hline
\end{tabular}

Source: Hendel et al (2009). Coefficient standard errors and hedonic price regression Nobs in parentheses

\section{$\underline{\text { Parameters }}$}

In the enhanced simulated model, let the daily arrival rate of buyers in each market be

$$
\beta=0.05
$$

which implies a buyer in a particular market arrives on average once every 20 days. Over a month, this rate (1.5) is marginally higher than the average (1.4) from Table 1 across the averaged quality class $\times$ elementary school markets in Madison. Normalize the gains to trade from buying a home so that $x=1$. The sunk cost to a seller is set equal to half this value:

$$
F=0.5
$$

The monthly rate of time preference is $r=0.0042$ which corresponds to a $5 \%$ annual rate. Potential sellers arrive at three times the buyer rate, $\alpha+\sigma=3 \beta$. Let one in every five potential sellers be $(\alpha)$ motivated or compelled to sell so that

$$
\begin{aligned}
& \alpha=\beta / 4=0.03 ; \\
& \sigma=2 \beta-\alpha=0.12
\end{aligned}
$$

The latter specification is broadly consistent with Anenberg and Bayer (2013) who find that the fraction of homes sold by movers within Los Angeles (movers who are more likely to be relaxed) was $20 \%$ during trough sales periods and $40 \%$ during boom sales periods. Buyers search costs are set to zero $d_{b}=0$. For reasons discussed below, two values for seller costs are considered:

$$
d_{s}^{L}=0.000975
$$

and

$$
d_{s}^{H}=1.5 \times d_{s}^{L}=0.001462 .
$$

The eight parameters $\left(\alpha, \beta, \sigma, x, F, r, d_{b}, d_{s}\right)$ describe a particular market. Using these parameters, the model for a given market can be solved numerically and then repeatedly simulated over time to obtain familiar market-wide statistics. Given the house quality $\times$ school configuration in Madison, let there be 150 identical, self-contained, small markets in which buyers and 
Figure 1: Monthly House Sales Frequency in Individual Markets
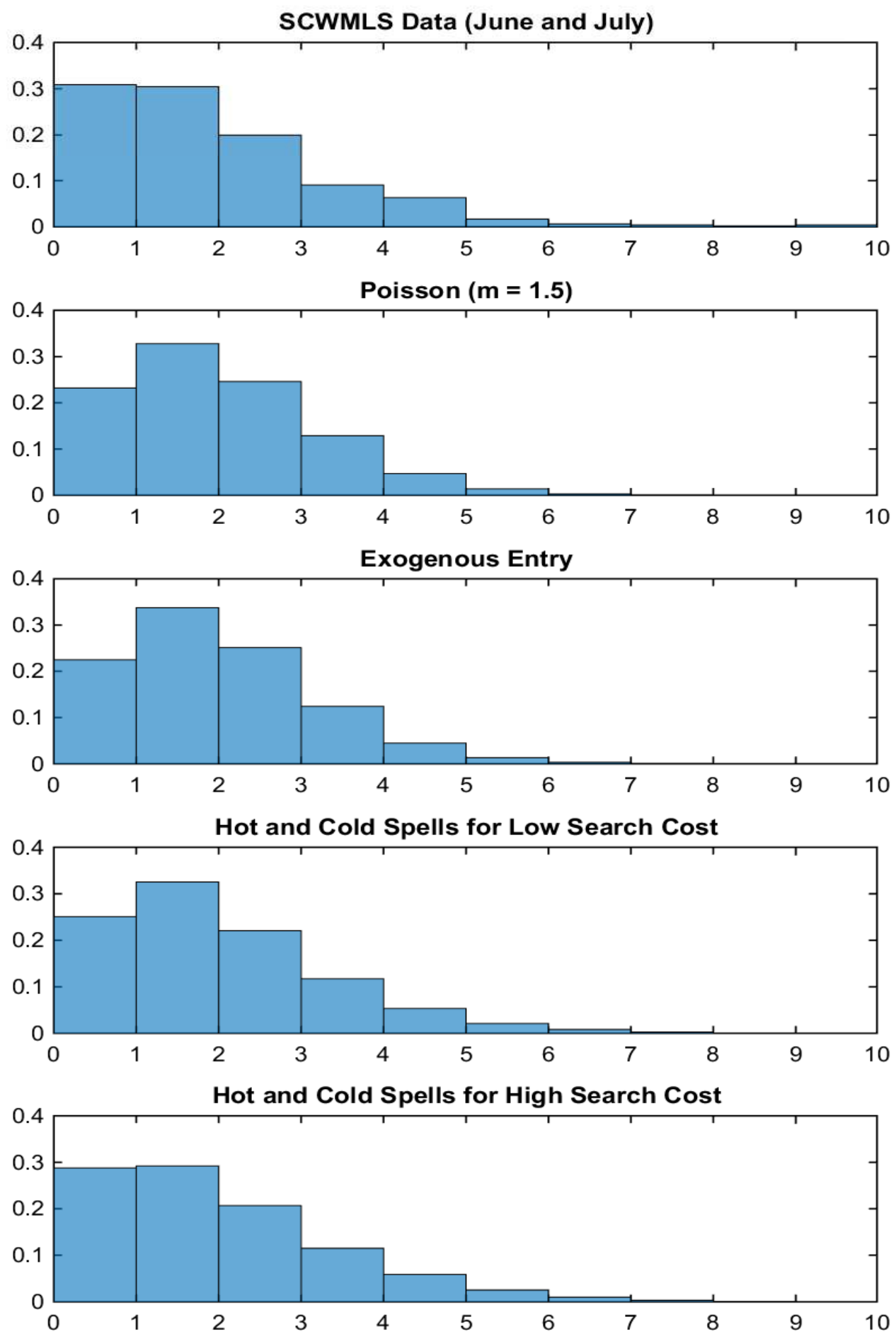
sellers arrive according to independent continuous time Poisson processes. This figure roughly matches aggregate sales.

In continuous time, Poisson arrival rates imply that the associated waiting times between buyers and between potential sellers are both distributed exponentially so that more than one trade does not take place at any one instant. The organization of simulated events, however, reflects observed data in that events are recorded in discrete intervals during which more than one sale can occur. In particular, the model is simulated for 240 intervals or discrete periods of 30 days each. The first 100 periods are dropped. Summing over the month and over individual markets yields area-wide monthly average prices, total sales, new listings, inventory of unsold homes and time on the market.

The parameters (or some subset) could in principle be estimated using minimum distance, moment fitting methods. Such an approach poses practical difficulties. The threshold number of traders will not always satisfy (A2). At some high seller costs for $F$ or $d_{s}$, profitable entry for sellers requires $N>2$ buyers. Adopting an endogenous threshold for when sellers enter vastly expands the model and its computing complexity. Given this and other quantitative limitations, ${ }^{20}$ the approach adopted here seems adequate for demonstrating that the model can deliver non-trivial hot and cold spells that lead to outcomes broadly consistent with observed regularities.

\section{Simulations}

Numerically solving for the endogenous variables for $d_{s}^{L}=0.000975$ gives

$$
\begin{aligned}
T_{1}^{L} & =39.6 \\
T_{0}^{L} & =67.6 \\
C\left(T_{1}^{L}\right) & =0.499
\end{aligned}
$$

Given lower seller search $\operatorname{costs} d_{s}^{L}$, the duration of a cold spell with one known buyer in a market is over a month plus a week. The duration of a cold spell when there are no known buyers is two months plus a week. Given $\beta=0.05$, the probability that no new buyers show up over $T_{1}^{L}$ is approximately one seventh hence the likelihood that at least two (new plus old) buyers are in the market after a $T_{1}^{L}$ spell is 0.8618 . After a duration of $T_{0}^{L}$, the probability that there will be two (both new) or more buyers is nearly the same value 0.8508 whereas the probability of at least one new buyer is close to one (0.9659). As a result, sellers with the option of entry will infrequently find themselves without at least one buyer and therefore the inventory stock of unsold homes derives primarily from motivated sellers entering cold markets.

\footnotetext{
${ }^{20}$ It is unclear how to weigh the relative importance of variation, correlation and persistence of potential variables against each other, and against the distribution of markets without trade, the key to using Dane County data. The lack of heterogeneity across buyers, the absence of spillovers across the many small markets and the other abstractions in the model compound this challenge.
} 
Higher search costs for sellers, $d_{s}^{H}=0.001462$, yield higher waiting times and lower payoffs

$$
\begin{aligned}
T_{1}^{H} & =59.3 \\
T_{0}^{H} & =86.4 \\
C\left(T_{1}^{H}\right) & =0.530
\end{aligned}
$$

The higher seller search costs raise the respective waiting periods to approximately two and three months.

As a first yardstick, both specifications with cold spells exhibit plausible levels of competition among buyers. In the low cost $d_{s}^{L}$ specification, the proportion of houses sold in competitive auctions with two or more bidders is just below half - 0.494. In the high cost $d_{s}^{L}$, this figure rises above one half to 0.530. Using data from the real estate brokerage firm Redfin, Arefeva (2017) finds that between 2009 and 2016, on average half the buyer offers faced a competing bid. Excluding the extremely low competition from 2009, this average becomes a bit further above half and ranges from roughly 0.40 to $0.75 .^{21}$

Table 3 presents further simulation results. The first column presents the SCWMLS benchmark Dane/Madison figures, logged, detrended and seasonally adjusted to facilitate comparison with the stationary model. ${ }^{22}$ The following three columns present statistics from different specifications of the model. To benchmark outcomes without hot and cold spells, the first shuts down the seller entry decision. This specification is not only closely related to Caplin and Leahy (2011) (as noted in Section 2) but also corresponds to Coles and Muthoo (1998) and other stock-flow matching models in which there are no relaxed sellers, i.e. $\sigma=0$. To maintain a well behaved economy in this specification requires equal entry rates for buyers and motivated sellers so that $\alpha=\beta=0.05$. The next two specifications have discretionary (relaxed) seller entry - hence hot and cold cycles. These two correspond to the model with endogenous entry under the two different values of seller search costs, $d_{s}^{L}<d_{s}^{H}$. (The appendix provides other statistics and discussion for the $d_{s}^{L}$ case.)

The assessment of these results proceeds in three steps. The first step groups and considers together the aggregated market-wide variation, correlation and persistence in the sales-price measures highlighted above that suggest the presence of hot and cold trading. In particular, the top three rows of Table 3 present the standard deviation over time in total sales, the contemporaneous correlation of these sales with average prices and the one month autocorrelation of average price. $^{23}$

The second stage of the assessment focuses on the unique strength of these data - the underlying direct evidence of cold spells during which no sales occur. The fourth row in Table

\footnotetext{
${ }^{21}$ No data on the number of offers are available for the SCWMLS data. For the exogenous seller entry simulations, this figure is time dependent. The distribution of a Poisson minus a Poisson is a Bessel distribution centered about zero that spreads out symmetrically over time. Thus, the proportion of competitive bids is necessarily less than one half, starts small, but limits to one half after sufficient time passes.

${ }^{22}$ OLS regressions with a linear trend and monthly dummies are used to detrend and seasonally adjust all logged variables. The general picture of relative standard deviations is similar but less pronounced when the variables are not detrended and seasonally adjusted.

${ }^{23}$ Price variation is not assessed. The model finds the share of the gains from trade whereas the price itself reflects the value of the asset to the buyer. These are different concepts.
} 
3 therefore reports the ratio $p_{0} / p_{1}$ of zero house sales to one house sale recorded in a month, averaged over time and across all individual markets. ${ }^{24}$ The bottom three panels of Figure 1 complement this statistic by plotting the distribution of sales across markets from the three simulated models.

The third step in this analysis turns to other statistical relationships often put forward in the housing literature. The duration of search, i.e. liquidity, is one often used measure. To gauge this measure, rows five through seven in Table 3 report the mean, standard deviation, and comovement (with price) for time on the market (ToM). As discussed in Caplin and Leahy (2011), in the housing and job markets, another key statistic is the availability of trade. Therefore, the last row in Table 3 reports the correlation of price with lagged inventory (Inv). Inventories arise when motivated sellers enter a cold market, do not find an available buyer, and then wait for buyers. Time on the market as well as inventories are thus proxy measures for the extent of cold markets.

Hot markets have excess buyers bidding high prices for rapidly sold houses. In contrast, cold markets exhibit slower seller entry along with monopoly buyers making low bids potentially to an inventory of unsold houses that are lingering about. As a result, in markets with more prolonged cold spells, prices and sales will become more variable and more positively correlated with each other. Moreover, as cold spells last longer, prices and sales stay lower for longer thereby raising price persistence as well as diminishing observed liquidity. Table 3 reveals these relationships and more significantly that they fit better with observations from the SCWMLS data.

Based on the first three measures of variation, co-movement and persistence in Table 3, the model without hot and cold spells performs poorly. This specification has the least variation in sales. It also displays a low correlation of price with sales, and no autocorrelation in price. ${ }^{25}$ The two specifications with hot and cold spells both improve upon these measures. In both versions with discretionary seller entry, the standard deviation in sales rises and becomes closer to the SCWMLS observation. The co-movement of prices with sales and price persistence are likewise more pronounced and more in line with observed outcomes. Although the simulated price-sales correlation with hot and cold spells is higher than that observed in Dane County, the Dane County measure is less than found elsewhere from more aggregated, longer but less frequent, and sometimes trending series. ${ }^{26}$.

Turning to the direct measures of cold spells, the simulated $p_{0} / p_{1}$ ratio without entry is approximately the figure that would obtain given random matching. As discussed above, random matching does not perform well in this regard. Relative to the SCWMLS data, there are not only too few large sale months but also too few months with zero sales. In contrast, the $p_{0} / p_{1}$ ratio improves in both models with entry. Both specifications exhibit a higher $p_{0} / p_{1}$ ratio. This ratio in the high cost $d_{s}^{H}$ specification nearly equals the value observed in the SCWMLS data.

\footnotetext{
${ }^{24}$ For the SCWMLS, the ratio $p_{0} / p_{1}$ statistics comes from using the sample of markets with similar numbers of sales. As in the negative binomial regression, the sample uses only June and July sales and includes only those markets with June and July sales within a quarter of median sales. Again, for this sample Nobs $=476$.

${ }^{25}$ These latter statistics are unstable. They vary considerably across simulation runs.

${ }^{26}$ See Stein (1995), Ortalo-Magné and Rady (2006), Díaz and Jerez (2013) and Ngai and Sheedy (2015). An exception is Head et al (2014) with a negative price-sales relationship.
} 
The bottom three panels of Figure 1 further support this finding. The frequencies of zero sales and of a high number of sales increases with hot and cold spells. In addition, it is also possible to calculate the number of months in which a seller actually refuses entry, either with one or zero known buyers. Given $d_{s}^{L}$, the proportion of months $\times$ markets that experience at least one relaxed seller declining entry during a $T_{1}$ cold spell is 0.353 . The proportion for $T_{0}$ spells is 0.4333 .

Table 3. SCWMLS Data and Model Simulations

\begin{tabular}{lcccc}
\hline & SCWMLS & Exogenous & \multicolumn{2}{c}{ Hot Cold Spells } \\
& Data & Entry & $d_{s}^{L}$ & $d_{s}^{H}$ \\
\cline { 2 - 5 } SD (Sales) & 0.114 & 0.068 & 0.074 & 0.075 \\
Corr(Sales,Price) & 0.219 & 0.113 & 0.237 & 0.384 \\
AutoCorr(Price) & 0.332 & -0.004 & 0.399 & 0.377 \\
$p_{0} / p_{1}$ & 1.014 & 0.668 & 0.767 & 0.983 \\
Mean(ToM) & 66 & 36.8 & 32.2 & 29.6 \\
SD(ToM) & 0.081 & 0.103 & 0.245 & 0.244 \\
Corr(Price,ToM) & -0.085 & -0.316 & -0.385 & -0.403 \\
Corr(Price,lag(Inv)) & -0.111 & 0.256 & -0.341 & -0.271 \\
\hline
\end{tabular}

The set of measures in the last four rows of Table 3 continue painting a similar picture. All three simulated models have an average duration on the market of a month or so which accounts for roughly half the time observed to complete a trade. There are, of course, several factors that will also contribute to these trading delays. The variation in time on the market is higher in the simulated data than in the limited SCWMLS data. Although this excess dispersion is more pronounced with hot and cold spells, the SCWMLS measure is lower than in other studies. Díaz and Jerez (2013) find that the time on the market variation is nearly twice the sales variation. Ngai and Sheedy (2015) find that time to sale - a different but related measure - is twice the price variation.

The housing literature often explores the link between price and time on market. Here the model differs from the SCWMLS data. In all three versions of the model, the correlation is negative and prominent. The correlation is weakly negative in Dane County data. Time on the market in the SCWMLS is calculated over a relatively short time period. Moreover, the absence of this co-movement in the SCWMLS data is out of line with the relationship obtained elsewhere. Several authors document and emphasize a robust negative relationship between price and time on the market or with time to sell linked with hot and cold markets. ${ }^{27}$ The pronounced inverse relationship in the simulations conforms with evidence of a strong inverse relationship perceived as stylized fact. See Ngai and Sheedy (2015), Díaz and Jerez (2013), Krainer (2008), Novy-Marx (2009).

\footnotetext{
${ }^{27}$ Average time on the market, which measures the average duration a home in the unsold stock available has been on the market, differs from the average time to sell, which measures how long a house took to sell among the flow of houses leaving the market.
} 
The simulations with hot and cold spells also yield the negative price-lagged inventory relationship highlighted by Caplin and Leahy (2011). ${ }^{28}$ This relationship is positive when relaxed sellers can choose whether to enter. With this entry decision available, the correlation exceeds the measure found in Dane County. Indeed, the simulations with entry generally exhibit stronger correlations than observed in Dane County which may in part reflect the impact of detrending and seasonally adjusting the SCWMLS data.

Although the $d_{s}^{H}$ specification performs best in several dimensions, an underlying difficulty highlights the quantitative limitation of using the stylized model. Under these parameters, the imposed and fairly natural threshold between one and two bidders does not hold. The price in a two bidder sale is less than the entry fee, $P(1)>F$, which violates (A2). Although the violation is modest (0.03), it implies that sellers would not obtain a profit from two buyers. Sellers want to wait even further for additional buyers (Caplin and Leahy (2011) explore this possibility), an outcome that would intuitively appear to induce even more dispersion in sales. None the less, this specification suggests that sufficiently lengthy cold spells can be found that begin to line up with the dispersion in sales with observation.

Improving the empirical content requires an extensive expansion of the model and a more sophisticated empirical approach. On the other hand, the increasing availability of high frequency trading data could spur further interest in the empirical performance of this framework. For example, REDFIN allows downloading data for a large number of MSAs in the United States from 2009 onwards. One can readily observe differences across time and place. It is intriguing to consider what parameter differences could account for the variation.

Table 4 offers a more modest investigation - a brief robustness/comparative static exercise. Using the lower seller search cost specification $d_{s}^{L}$, Table 4 presents simulated outcomes for different values of two other cost parameters. In particular, the fixed entry cost for the seller is lowered to $F=0.4$, down from $F=0.5$. In addition, as the interest rate $r$ contributes to both buyer and seller impatience and hence eagerness to trade (along side $d_{s}$ ), the table presents the key figures simulated for a lower, the same, and a higher interest rate.

The middle column of Table 4 corresponds to the initial interest rate specified in Table 3. (The adjacent figures in parentheses in this column are the figures from Table 3, i.e. from the model with higher fixed entry costs for the sellers.) Lowering entry costs $F$ by twenty percent decreases the $T_{1}$ induced cold spell by almost two weeks which is nearly a third of the original spell. The decline in the $T_{0}$ induced cold spell is approximately the same number of days which is slightly less than twenty percent of the original value so that this elasticity is just less than one.

The impact of lower entry cost and the accompanying shorter cold spells on market observations is to marginally lower sales dispersion while more notably raising the correlation of sales with price and the autocorrelation of prices. These last two two figures thus become more distant from the SCWMLS data. The $p_{0} / p_{1}$ ratio likewise moves substantially away from its data target. The mean and standard deviation of time on the market rise, the correlation of

\footnotetext{
${ }^{28}$ In their baseline model which shares aspects of this model but does not have hot and cold spells, Caplin and Leahy are unable to explain positive autocorrelation in prices or a negative correlation between price and lagged inventory.
} 
price with the time on market becomes less negative whereas the correlation of price with lagged inventory rises. While these last four are a mixed bag of outcomes compared the SCWMLS data, recall that these data are somewhat limited and not entirely consistent with other data sources. Note as well that the proportion of competitively sold houses (with two or more bidders) falls further from the observations from Arefeva (2017).

Reading from left to right across Table 4, a rising interest rate lowers the buyer's expected payoff in the cold spell. Lower buyer payoffs are accompanied by shorter spells before sellers become willing to enter which in turn change the observable data measures without much surprise. As the cold spells become shorter, the variation in sales, the co-movements of price with sales and of price with lagged inventories, and the autocorrelation of prices all become smaller. The proportion of sales with two or more bidders also falls. Exceptions come from outcomes involving time on the market. The mean time on the market rises with the interest rate but its variation and co-movement with price exhibit inverted U-shaped patterns as the interest rate increases. It is also worth noting that the figures from the low interest cost coupled with lower entry costs are similar in several cases to the baseline model figures.

Table 4. Model Simulations for Lower Entry Cost $(\mathrm{F}=0.4)$

\begin{tabular}{|c|c|c|c|}
\hline & $r=0.04 / 12$ & $r=0.05 / 12(F=0.5)$ & $r=0.06 / 12(F=0.5)$ \\
\hline$C\left(T_{1}\right)$ & 0.600 & $0.576 \quad(0.499)$ & $0.562(0.482)$ \\
\hline$T_{1}$ & 40.1 & $27.5(39.6)$ & $21.7(30.7)$ \\
\hline$T_{0}$ & 68.4 & $55.0(67.6)$ & $48.4(58.2)$ \\
\hline SD (Sales) & 0.074 & $0.070(0.074)$ & $0.069 \quad(0.69)$ \\
\hline Corr(Sales,Price) & 0.360 & $0.284 \quad(0.237)$ & $0.226 \quad(0.221)$ \\
\hline AutoCorr(Price) & 0.4463 & $0.441 \quad(0.399)$ & $0.379 \quad(0.350)$ \\
\hline$p_{0} / p_{1}$ & 0.794 & $0.597 \quad(0.767)$ & $0.564 \quad(0.638)$ \\
\hline Mean(ToM) & 33.0 & $38.4(32.2)$ & $39.5(36.6)$ \\
\hline $\mathrm{SD}(\mathrm{ToM})$ & 0.244 & $0.259 \quad(0.245)$ & $0.228(0.245)$ \\
\hline Corr(Price,ToM) & -0.331 & $-0.259(-0.385)$ & $-0.348(-0.378)$ \\
\hline Corr(Price,lag(Inv) & -0.398 & $-0.394(-0.341)$ & $-0.347(-0.365)$ \\
\hline $\operatorname{Pr}($ Bidders $\geq 2))$ & 0.494 & $0.456 \quad(0.494)$ & $0.430 \quad(0.476)$ \\
\hline
\end{tabular}

Note: Figures in parentheses are simulated results for $F=0.5$

\section{Conclusion}

Profit attracts entry. In perfectly competitive markets with full information, instantaneous erosion of profit pins down the timing and number of entrants as well as the price and quantity sold. In markets with frictions, entry and the subsequent pattern of trade may not be as immediate nor as straightforward. Depending on market structure, it may take time to uncover 
profitable opportunities which in turn affects the ability and willingness of agents to exchange goods and services.

This paper investigates the way in which entry of this sort affects housing markets with stockflow matching. Home buyers compete in complete information auctions for homes brought to market one by one. To attract home seller entry, there must be sufficient competition among these bidders. Bertrand-like offers from two bidders are sufficient to induce entry. One monopolistic buyer is not.

Given that house sellers can enter more rapidly than home buyers, markets will alternate between periods of active and inactive entry. In cold markets, prospective sellers pass up production opportunities as they wait for the (unobserved) arrival of buyers to replenish the market. Once they think enough time has passed, entry resumes and reveals the profits to be made in the market. Seller entry continues until it exhausts the existing demand.

The periods of inactivity are inefficient. With one willing but monopolistic bidder, gains to trade exist but are passed over because sellers do not obtain a sufficient share of this payoff. In particular, sellers will want to cover an up-front sunk cost which a monopolistic bidder cannot commit to paying before entry takes place. With Bertrand numbers, buyers are compelled to bid above the sunk cost making entry profitable.

Simulated outcomes align with empirical evidence from Dane County, Wisconsin as well as stylized facts established in the literature. The simulated variation in sales, the correlation of price with sales and the persistence in price improve as hot and cold spells become more pronounced. Likewise, hot and cold spells improve the fit of correlations of price with time on the market and with inventory. Perhaps more fundamentally, the simulated outcomes are consistent with the high frequency of periods of inactivity in precisely defined areas.

To conclude this picture, it is worth looking again at the underlying data for Madison and considering stock-flow generally. Ortalo-Magné (2011) looks in detail at a particular homogeneous market in Madison - large houses in a single elementary school district - which conforms closely to the specification of a single market in this paper. Figure 2 reproduces Ortalo-Magné's observations of price premia ${ }^{29}$ and the number of available houses on the market during the period January 1999 until December 2004. Viewed through the lens of stock-flow trade, this plot is intriguing. Two episodes stand out given the focus on hot and cold spells. Between December 2000 and December 2001, the Ortalo-Magné figure displays only two price premia (hence sales) both of which occur shortly after the addition of a new home for sale, one after a month and the other after two months. It looks as if a seller entered a cold market and was able to sell to an eager buyer. In the eight months between July 2001 and March 2002, no sales appear to take place. In the second episode from September 2003 until January 2005, again only two price premia appear. Within this period, no sales take place in the ten months between September 2003 and June 2004 during which time two house were added to the inventory for sale. It looks as if in this instance sellers entered during a dry patch in turnover but did not find a buyer willing to trade quickly.

\footnotetext{
${ }^{29}$ The price premium is the ratio of the transaction price to a hedonic regression adjusted price minus one.
} 
Figure 2: Price and Monthly Sales in a Single Market

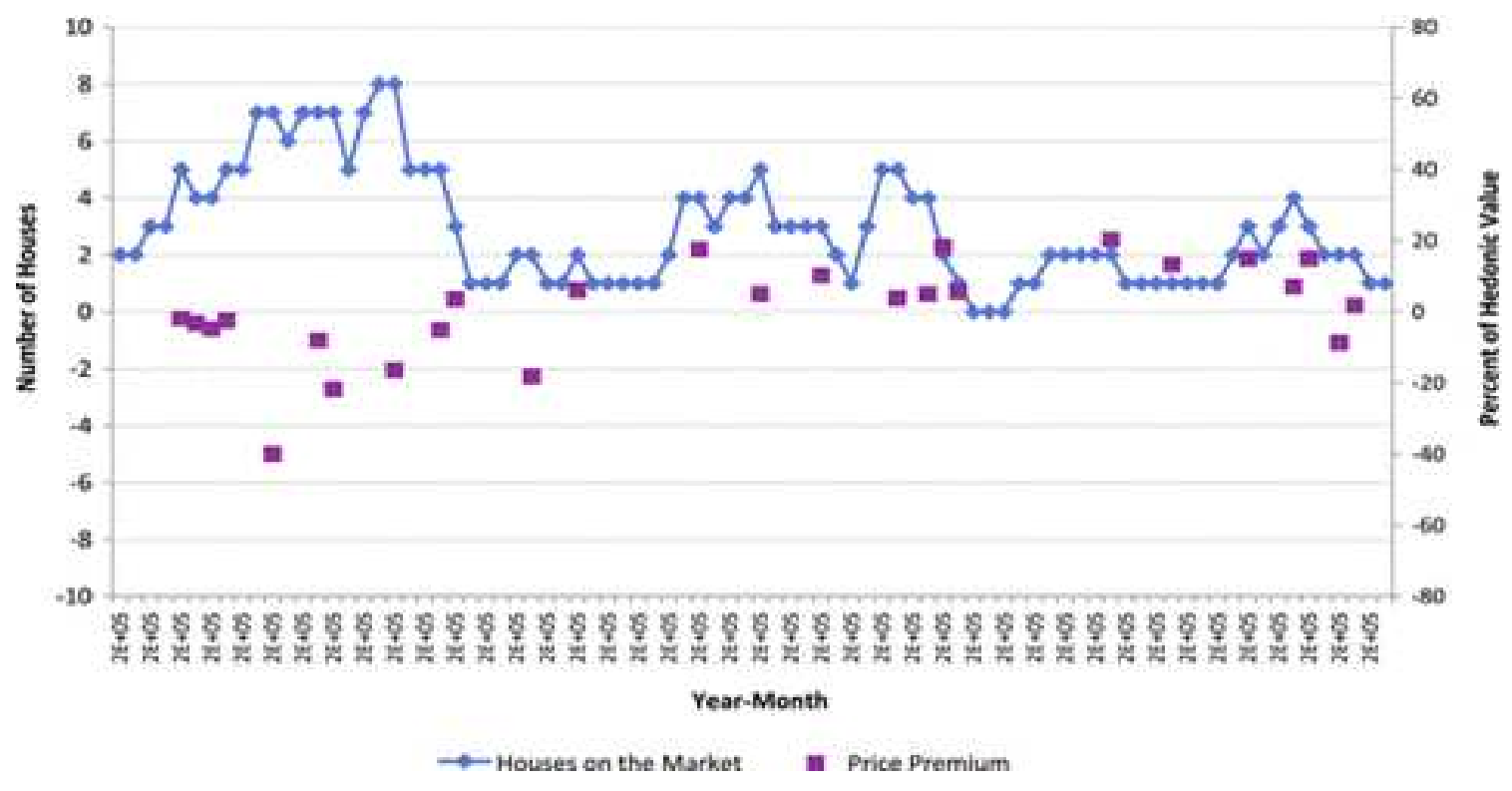


Acknowledgements I would like to thank two anonymous referees, the Associate Editor, Alina Arefeva, Melvyn Coles and numerous participants at the Essex Search and Matching workshop, the SaM conference, the Society for Economic Dynamics conference, and the Bank of England, the Federal Reserve Bank of Atlanta and the University of Bristol seminar series for helpful comments and discussions. The usual disclaimer applies. 


\section{References}

[1] Albrecht, J., A. Anderson, E. Smith, and S. Vroman (2007), "Opportunistic matching in the housing market," International Economic Review, 48: 641-663.

[2] Albrecht, J., P. Gautier, and S. Vroman (2016), "Efficient entry in competing auctions," American Economic Review, 104: 3288-96.

[3] Andrews, M., S. Bradley, D. Stott, and R. Upward (2013), "Estimating the stock-flow matching model using micro data," Journal European Economic Association, 11: 1153-1177

[4] Anenberg, E. and P. Bayer (2013), "Endogenous sources of volatility in housing markets: The joint buyer-seller problem," NBER Working Paper 18980

[5] Arefeva, A. (2017), "How auctions amplify house-price fluctuations," Carey Business School Research Paper No. 17-12

[6] Arnold, M. and S. Lippman (1995), "Selecting a selling institution: Auctions versus sequential search," Economic Inquiry, 33: 1-23.

[7] Burnside, C., M. Eichenbaum, and S. Rebelo (2016), "Understanding booms and busts in housing markets," Journal of Political Economy, 124: 1088-1147.

[8] Caplin, A. and J. Leahy (2011), "Trading frictions and house price dynamics," Journal of Money, Credit and Banking, 43: 283-303.

[9] Carrillo-Tudela, C. and L. Visschers (2013), "Unemployment and Endogenous Reallocation over the Business Cycle", IZA Discussion Papers No. 7124.

[10] Case, K. and R. Shiller (1989), "The efficiency of the the market for single-family homes," American Economic Review, 79: 125-37.

[11] Coles, M. and A. Muthoo (1998), "Strategic bargaining and competitive bidding in a dynamic market equilibrium," Review of Economic Studies, 65: 235-260

[12] Coles, M. and B. Petrongolo (2008), "A test between unemployment theories using matching data," International Economic Review,49: 1113-1149.

[13] Coles, M. and E. Smith (1998), "Marketplaces and matching," International Economic Review, 39: 239-255.

[14] Davis, M. and J. Heathcote (2008), "The price and quantity of residential land in the United States," Journal of Monetary Economics, 54: 2595-2620.

[15] Díaz, A. and B. Jerez (2013), "House prices, sales and time on the market: A searchtheoretic framework," International Economic Review, 54:837-872.

[16] Ebrahimy, E. and R. Shimer (2010), "Stock-flow matching," Journal of Economic Theory, 145: $1325-1353$. 
[17] Genesove, D. and C. Mayer (1997), "Equity and time to sale in the real estate market," American Economic Review, 87: 255-69.

[18] Glaeser, E., J. Gyourko, J. Morales, and C. Nathanson (2014), "Housing dynamics: An urban approach, "Journal of Urban Economics 81: 45-56.

[19] Glaeser, E., J. Gyourko, and A. Saiz (2008), "Housing supply and housing bubbles," Journal of Urban Economics, 64: 198217.

[20] Gregg, P. and B. Petrongolo (2005), "Stock-flow matching and the performance of the labour market," European Economic Review, 49: 1987-2011.

[21] Gyourko, J. and A. Saiz (2006), "Construction costs And the supply of housing structure," Journal of Regional Science, 46: 661-680.

[22] Halket, J. and M. di Custoza, (2015), "Homeownership and the scarcity of rentals, "Journal of Monetary Economics, 76: 107-123.

[23] Han, L. and W. Strange (2015), "The microstructure of housing markets: Search, bargaining, and brokerage," Handbook of Regional and Urban Economics, 5B: 813-886.

[24] Haurin, D. (1988), "The duration of marketing time of residential housing, "Real Estate Economics, 16: 396-410.

[25] Head, A., H. Lloyd-Ellis, and H. Sun (2014), "Search, liquidity and the dynamics of house prices and construction," American Economic Review, 104: 1172-1210.

[26] Hedlund, A. (2016), "The cyclical dynamics of illiquid housing, debt, and foreclosures," Quantitative Economics, 7: 289328.

[27] Hendel, I., A. Nevo, and F. Ortalo-Magné (2009), "The relative performance of real estate marketing platforms: MLS versus MSBOMadison.com," American Economic Review, 99: 1878-98.

[28] Krainer, J. (2001), "A theory of liquidity in residential real estate markets," Journal of Urban Economics, 49: 32-53.

[29] Krainer, J. (2008), "Falling house prices and rising time on the market," FRBSF Economic Letter, Federal Reserve Bank of San Francisco, March

[30] Kuo, M. and E. Smith (2009), "Marketplace matching in England and Wales: Evidence from individual unemployment spells," Labour Economics, 16: 37-46.

[31] Lagos, R. (2000), "An alternative approach to search frictions," Journal of Political Economy, 108: 851-73.

[32] Landvoigt, T., M. Piazzesi, and M. Schneider (2015), "The housing market (s) of San Diego," American Economic Review, 105: 1371-1407. 
[33] Muelbauer, J. and A. Murphy (1997), "Booms and busts in the U.K. housing market," Economic Journal, 107: 1701-1727.

[34] Ngai, R. and K. Sheedy (2015), "Ins and Outs of Selling Houses," mimeo, London School of Economics.

[35] Ngai, R. and S. Tenreyro (2014), "Hot and cold seasons in the housing market," American Economic Review, 104: 3991-4026.

[36] Novy-Marx, R. (2009), "Hot and cold markets," Real Estate Economics, 37: 1-22.

[37] Ortalo-Magné, F. (2011), "Discussion of 'Trading frictions and house price dynamics'," Journal of Money, Credit and Banking, 43: 304-309.

[38] Ortalo-Magné, F. and S. Rady (2006), "Housing market dynamics: On the contribution of income shocks and credit constraints," Review of Economic Studies, 73: 459-85.

[39] Piazzesi, M., M. Schneider, and J. Stroebel (2017), "Segmented housing search,"mimeo, Stanford University

[40] Pissarides C. (2000), Equilibrium Unemployment Theory, MIT Press: Cambridge, Second Edition.

[41] Saiz, A. (2010), "The geographic determinants of housing supply," Quarterly Journal of Economics, 125: 1253-1296.

[42] Shiller, R. (1982), Market volatility, MIT Press: Cambridge.

[43] Shimer, R (2007), "Mismatch," American Economic Review, 97: 1074-1101.

[44] Smith, E. (2007), "Limited duration employment," Review of Economic Dynamics, 10: 444471

[45] Stein, J. (1995), "Prices and trading volume in the housing market: a model with downpayment effects," Quarterly Journal of Economics, 110: 379-406

[46] Taylor, C. (1995), "The long side of the market and the short end of the stick: bargaining power and price formation in buyers', sellers' and balanced markets," Quarterly Journal of Economics, 110: 837-855.

[47] Wang, R. (1993), "Auctions versus posted-price selling," American Economic Review, 83: 838851.

[48] Wheaton, W. C. (1990), "Vacancy, search, and prices in a housing market matching model," Journal of Political Economy, 98: 127092 


\section{Appendix}

\section{Proofs}

\section{$\underline{\text { Lemma } 1}$}

$P(0)$ : When there is only one bidder at entry, cold market behaviour implies that seller but not buyer entry ceases until this particular transaction occurs. To find a seller's reservation threshold in this situation note that the bidder offers the price $P(0)$ that makes the lone seller indifferent between accepting now and waiting for another bidder to arrive and bid $P(1)$. Accounting for the potential state change from buyer entry, the equilibrium bid that makes the seller indifferent can be written as

$$
P(0)=Z(0)=\frac{1}{1+r d t}[\beta d t P(1)+(1-\beta d t) P(0)]
$$

so that

$$
P(0)=\frac{\beta}{r+\beta}
$$

$P(N), N \geq 1$ : In a full information Bertrand pricing game with more than one bidder, buyers bid up prices until the buyer's gain to trade from purchasing the currently available good equals the payoff of staying in the market and waiting for the next auction. In particular, the buyer's payoff in an auction with another bidder $(N=1)$ is

$$
\max _{P}\left\{I\left[P>P_{-1}\right]\left(x-P-C\left(T_{1}\right)\right)+I\left[P=P_{-1}\right]\left(\frac{x-P-C\left(T_{1}\right)}{2}\right)\right\}+C\left(T_{1}\right)
$$

whereas for $N \geq 2$, this payoff is given by

$$
\max _{P}\left\{I\left[P>P_{-N}\right](x-P-H(N))+I\left[P=P_{-N}\right]\left(\frac{x-P-H(N)}{N+1}\right)\right\}+H(N)
$$

where the other buyers offer at least the seller's reservation wage in this auction, $P_{-N} \geq Z(N)$.

The best response strategy $P(N)$ is to offer just above $P_{-N}$ until $P(N)$ reaches the buyer's reservation threshold. At this offer limit, the buyer is indifferent between buying the house and waiting. QED

\section{$\underline{\text { Lemma } 2}$}

$H(1)$ : A lone bidder receives $x-P(0)$ if seller entry occurs and $H(2)$ if buyer entry occurs. Accounting for arrival rates, this expected payoff can be written as the linear difference equation:

$$
H(1)=\frac{1}{1+r d t}[\sigma d t(x-P(0))+\beta d t H(2)+(1-\sigma d t-\beta d t) H(1)]
$$

$H(2)$ : With one other waiting bidder, seller entry results in an auction that leaves one known, unsatisfied bidder remaining for the next auction. This outcome stops the entry of sellers and leaves the unsatisfied bidder in a cold market with expected payoff $C\left(T_{1}\right)$. The successful bid with two bidders leaves them indifferent between buying and remaining, $x-P(1)=C\left(T_{1}\right)$. Alternatively, buyer entry yields $H(3)$, hence the payoff to a buyer in an active market with two 
bidders is given by

$$
H(2)=\frac{1}{1+r d t}\left[\sigma d t C\left(T_{1}\right)+\beta d t H(3)+(1-\sigma d t-\beta d t) H(2)\right]
$$

$H(N), N \geq 3$ : Competitive bidding here makes buyers indifferent between purchasing and waiting in a hot market for the next auction with one less competitor. Hence, seller entry yields $H(N-1)$. As buyer entry yields $H(N+1)$,

$$
H(N)=\frac{1}{1+r d t}[\sigma d t H(N-1)+\beta d t H(N+1)+(1-\sigma d t-\beta d t) H(N)]
$$

Applying the quadratic formula, this linear second order difference equation has stable root $\eta$.

Plugging in the solution for $H(3)$ yields $H(2)$. Substituting for $H(2)$ in $H(1)$ gives the payoff to a lone monopolistic buyer in an active market. QED

\section{$\underline{\text { Lemma } 3}$}

In state $N \geq 1$, rejection followed by accepting the price offered in the next instant yields

$$
Z(N)=\frac{1}{1+r d t}[\beta d t P(N+1)+\sigma d t P(N-1)+(1-\beta d t-\sigma d t) P(N)]
$$

The payoff for the first seller to a one period delay followed by accepting the price offered next period is given by

$$
\begin{aligned}
Z(N) & =\frac{1}{1+r d t}[\beta d t P(N+1)+\sigma d t P(N-1)+(1-\beta d t-\sigma d t) P(N)] \\
& =\frac{1}{1+r d t}[\beta d t(x-H(N+1))+\sigma d t(x-H(N-1))+(1-\beta d t-\sigma d t)(x-H(N))] \\
& =\frac{x}{1+r d t}-[\beta d t H(N+1)+\sigma d t H(N-1)+(1-\beta d t-\sigma d t) H(N)] \\
& =\frac{x}{1+r d t}-H(N)<x-H(N)=P(N)
\end{aligned}
$$

Similar calculations hold for delays by sellers of two periods or more which completes the proof. Note as well that $Z(N)=P(N)$ as $d t \rightarrow 0$. QED

\section{$\underline{\text { Lemma } 5}$}

The last step in the proof of Proposition 1 also establishes this result.

Proposition 1:

Plugging in the formulas for $H(N)$ and the monopoly price

$$
P(0)=\beta P(1) /(r+\beta)=\beta\left[x-C\left(T_{1}\right)\right] /(r+\beta)
$$

into the cold market payoff formula yields a first expression in two unknowns - $T_{1}$ and $C\left(T_{1}\right)$ :

$$
\Lambda_{*}\left(T_{1}\right) C\left(T_{1}\right)=\frac{r \sigma}{(r+\beta)(r+\sigma+\beta))} x
$$


where

$\Lambda_{*}\left(T_{1}\right)=\left[e^{(r+\beta) T}-\frac{\beta \sigma}{(r+\beta)(r+\sigma+\beta))}-\frac{\beta \sigma}{(r+\sigma+\beta)(r+\sigma+\beta(1-\eta))}-\frac{\sigma\left(e^{\beta \eta T}-1\right)}{\eta(r+\sigma+\beta(1-\eta))}\right]$

As

$$
\begin{gathered}
\Lambda_{*}^{\prime}\left(T_{1}\right)=e^{\beta \eta T_{1}}\left[r e^{r T_{1}}+\beta\left(e^{r T_{1}}-\frac{\sigma e^{-\beta(1-\eta) T_{1}}}{r+\sigma+\beta(1-\eta)}\right)\right]>0 \\
\Lambda_{*}(0)=\frac{r(r+\sigma+\beta)(r+\sigma+\beta(1-\eta))+\beta(r+\beta)(r+\beta(1-\eta))}{(r+\beta)(r+\sigma+\beta)(r+\sigma+\beta(1-\eta))}>0
\end{gathered}
$$

$C\left(T_{1}\right)$ in (5) is a strictly positive, downward sloping function of $T_{1}$ with strictly positive intercept

$$
C(0)=\frac{r \sigma(r+\sigma+\beta(1-\eta))}{r(r+\sigma+\beta)(r+\sigma+\beta(1-\eta))+\beta(r+\beta)(r+\beta(1-\eta))} x>0
$$

Next plugging in price $P(0)$ and $H(N)$ into the $R\left(1, T_{1}\right)$ revenue equation in Lemma 4 gives a second expression in the same two unknowns:

$$
e^{-\beta T_{1}}\left[\frac{r}{r+\beta} x+\Lambda_{* *}\left(T_{1}\right) C\left(T_{1}\right)\right]=x-F
$$

where

$$
\Lambda_{* *}\left(T_{1}\right)=\left[\frac{\beta}{r+\beta}+\beta T_{1}-\frac{\beta \sigma T_{1}}{\eta(r+\sigma+\beta(1-\eta))}+\frac{\sigma\left(e^{\beta \eta T_{1}}-1\right)}{\eta^{2}(r+\sigma+\beta(1-\eta))}\right]
$$

has derivatives

$$
\begin{gathered}
\Lambda_{* *}^{\prime}\left(T_{1}\right)=\beta\left[1+\frac{\sigma\left(e^{\beta \eta T_{1}}-1\right)}{\eta(r+\sigma+\beta(1-\eta))}\right]>0 \\
\Lambda_{* *}^{\prime \prime}\left(T_{1}\right)=\frac{\beta^{2} \sigma e^{\beta \eta T_{1}}}{r+\sigma+\beta(1-\eta)}>0
\end{gathered}
$$

Differentiation of (6) with respect to $C\left(T_{1}\right)$ gives $e^{-\beta T_{1}} \Lambda_{* *}\left(T_{1}\right)>0$. Differentiation with respect to $T_{1}$ yields

$$
-\beta(x-F)+e^{-\beta T_{1}} \Lambda_{* *}^{\prime}\left(T_{1}\right) C\left(T_{1}\right)
$$

The derivative

$$
\begin{aligned}
\frac{d}{d T_{1}} e^{-\beta T_{1}} \Lambda_{* *}^{\prime}\left(T_{1}\right) & =e^{-\beta T_{1}}\left[-\beta \Lambda_{* *}^{\prime}\left(T_{1}\right)+\Lambda_{* *}^{\prime \prime}\left(T_{1}\right)\right] \\
& =-\beta^{2} e^{-\beta T_{1}}\left[1+\frac{\sigma}{r+\sigma+\beta(1-\eta)}\left(\frac{e^{\beta \eta T_{1}}-1}{\eta}-e^{\beta \eta T_{1}}\right)\right] \\
& <-\beta^{2} e^{-\beta T_{1}}\left[1-\frac{\sigma}{r+\sigma+\beta(1-\eta)}\right]<0
\end{aligned}
$$

implies

$$
-\beta(x-F)+e^{-\beta T_{1}} \Lambda_{* *}^{\prime}\left(T_{1}\right) C\left(T_{1}\right)<-\beta\left[(x-F)-C\left(T_{1}\right)\right]
$$


Hence, in $(6) C^{\prime}\left(T_{1}\right)>0$ for $(x-F) / C\left(T_{1}\right)>1$. Moreover, as

$$
\Lambda_{* *}(0)=r /(r+\beta)>0
$$

the $C\left(T_{1}\right)$ intercept from $(6)$ is

$$
C(0)=x-(r+\beta) F / r
$$

Finally, it it easy to see that in (6)

$$
\lim _{T_{1} \rightarrow \infty} C\left(T_{1}\right)=\infty
$$

Thus, if the $C(0)$ intercept from (5) is less than the intercept from (6), i.e.

$$
F \leq \frac{\beta[r(r+\sigma+\beta(1-\eta))+\beta(r+\beta(1-\eta))] x}{r(r+\sigma+\beta)(r+\sigma+\beta(1-\eta))+\beta(r+\beta)(r+\beta(1-\eta))}
$$

then these two equations intersect exactly once with $C\left(T_{1}\right)>0$ and $T_{1}>0$. QED

Proposition 3

Total differentiation of equations (5) and (6) gives

$$
\begin{aligned}
& Q\left[\begin{array}{c}
d C\left(T_{1}\right) \\
d T_{1}
\end{array}\right]=\left[\begin{array}{cc}
\Lambda_{*}\left(T_{1}\right) & \Lambda_{*}^{\prime}\left(T_{1}\right) \\
(+) & (+) \\
e^{-\beta T_{1}} \Lambda_{* *}\left(T_{1}\right) & -\beta(x-F)+e^{-\beta T_{1}} \Lambda_{* *}^{\prime}\left(T_{1}\right) \\
(+) & (-)
\end{array}\right]\left[\begin{array}{c}
d C\left(T_{1}\right) \\
d T_{1}
\end{array}\right] \\
& =\left[\begin{array}{cc}
\frac{r \sigma}{(r+\beta)(r+\sigma+\beta)} & 0 \\
(+) & \\
1-\frac{r}{r+\beta} e^{-\beta T_{1}} & \\
(+) & -1
\end{array}\right]\left[\begin{array}{c}
d x \\
d F
\end{array}\right]
\end{aligned}
$$

The proof of Proposition 1 established the noted signs for the individual elements in matrix $Q$. As $\operatorname{det}[Q]<0$, it immediately follows that $d C\left(T_{1}\right) / d x>0, d C\left(T_{1}\right) / d F<0$, and $d T / d F>0$. To sign $d T_{1} / d x>0$, note that

$$
\begin{aligned}
& \operatorname{det}\left[\begin{array}{cc}
\Lambda_{*}\left(T_{1}\right) & \frac{r \sigma}{(r+\beta)(r+\sigma+\beta)} \\
e^{-\beta T_{1}} \Lambda_{* *}\left(T_{1}\right) & 1-\frac{r}{r+\beta} e^{-\beta T_{1}}
\end{array}\right] \\
= & \frac{e^{-\beta T_{1}}}{r+\beta} \operatorname{det}\left[\begin{array}{cc}
\Lambda_{*}\left(T_{1}\right) & \frac{r \sigma}{r+\sigma+\beta} \\
\Lambda_{* *}\left(T_{1}\right) & (r+\beta) e^{\beta T_{1}}-r
\end{array}\right] \\
= & \frac{e^{-\beta T_{1}}}{r+\beta}\left[(r+\beta) e^{\beta T_{1}} \Lambda_{*}\left(T_{1}\right)-r \Lambda_{*}\left(T_{1}\right)-\frac{r \sigma}{r+\sigma+\beta} \Lambda_{* *}\left(T_{1}\right)\right]
\end{aligned}
$$

$\underline{\text { Lemma }}$

$$
1-\frac{\sigma}{r+\sigma+\beta}-\frac{\beta \sigma}{(r+\sigma+\beta)(r+\sigma+\beta(1-\eta))}=\frac{r(r+\sigma+\beta(1-\eta))+\beta(r+\beta(1-\eta))}{(r+\sigma+\beta)(r+\sigma+\beta(1-\eta))}>0 .
$$


This Lemma implies

$$
\begin{aligned}
\frac{e^{-\beta T_{1}}}{r+\beta}\left\{(r+\beta) e^{\beta T_{1}} \Lambda_{*}\left(T_{1}\right)-r \Lambda_{*}\left(T_{1}\right)-\frac{r \sigma}{r+\sigma+\beta} \Lambda_{* *}\left(T_{1}\right)\right\}_{T_{1}=0} & = \\
\frac{\beta}{r+\beta}\left\{1-\frac{\sigma}{r+\sigma+\beta}-\frac{\beta \sigma}{(r+\sigma+\beta)(r+\sigma+\beta(1-\eta))}\right\}>0 & >0
\end{aligned}
$$

Differentiation gives

$$
\begin{aligned}
\frac{d}{d T_{1}}\left[(r+\beta) e^{\beta T_{1}} \Lambda_{*}\left(T_{1}\right)-r \Lambda_{*}\left(T_{1}\right)-\frac{r \sigma}{r+\sigma+\beta} \Lambda_{* *}\left(T_{1}\right)\right] & = \\
\beta(r+\beta) e^{\beta T_{1}} \Lambda_{*}\left(T_{1}\right)+(r+\beta) e^{\beta T_{1}} \Lambda_{*}^{\prime}\left(T_{1}\right) & -r \Lambda_{*}^{\prime}\left(T_{1}\right)-\frac{r \sigma}{r+\sigma+\beta} \Lambda_{* *}^{\prime}\left(T_{1}\right)
\end{aligned}
$$

Note that

(i) $(r+\beta) e^{\beta T_{1}} \Lambda_{*}^{\prime}\left(T_{1}\right)-r \Lambda_{*}^{\prime}\left(T_{1}\right)>0$

$$
\beta(r+\beta) e^{\beta T_{1}} \Lambda_{*}\left(T_{1}\right)-\frac{r \sigma}{r+\sigma+\beta} \Lambda_{* *}^{\prime}\left(T_{1}\right)=\beta(r+\beta) e^{\beta T_{1}} S_{*}\left(T_{1}\right)-\frac{r \beta \sigma}{r+\sigma+\beta} S_{* *}\left(T_{1}\right)
$$

where

$$
\begin{aligned}
S_{*}\left(T_{1}\right)=e^{(r+\beta) T_{1}}-\frac{\sigma}{r+\sigma+\beta}- & \frac{\beta \sigma}{(r+\sigma+\beta)(r+\sigma+\beta(1-\eta))} \\
& -\frac{\sigma}{\eta(r+\sigma+\beta(1-\eta))}\left(e^{\beta \eta T_{1}}-1\right)
\end{aligned}
$$

and

$$
S_{* *}\left(T_{1}\right)=e^{\beta T_{1}}-1-\frac{\sigma}{\eta(r+\sigma+\beta(1-\eta))}\left(e^{\beta \eta T_{1}}-1\right)
$$

The above Lemma implies $S_{*}(0)>0$ whereas

$$
S_{*}^{\prime}\left(T_{1}\right)=\beta e^{\beta T_{1}}\left[\frac{r+\beta}{\beta} e^{r T_{1}}-\frac{\sigma}{r+\sigma+\beta(1-\eta)} e^{-\beta(1-\eta) T_{1}}\right]>0
$$

In addition $S_{* *}(0)=0$ whereas

$$
S_{* *}^{\prime}\left(T_{1}\right)=\beta e^{\beta T_{1}}\left[1-\frac{\sigma}{r+\sigma+\beta(1-\eta)} e^{-\beta(1-\eta) T_{1}}\right]>0 .
$$

$S_{*}\left(T_{1}\right)>0$ and $S_{* *}\left(T_{1}\right)>0$ imply that

$$
\beta(r+\beta) e^{\beta T_{1}} \Lambda_{*}\left(T_{1}\right)-\frac{r \sigma}{r+\sigma+\beta} \Lambda_{* *}^{\prime}\left(T_{1}\right)>0
$$

thereby establishing $d T_{1} / d x<0$. QED 


\section{Motivated sellers and search costs}

With direct search costs $\left(d_{b}, d_{s}\right)$ and two types of sellers, price determination follows the same mechanics based on the payoffs during hot and cold spells. The payoffs to buyers and sellers, however, are more involved. In addition, the state of the market given by $(N, D)$, can have any number of sellers on the short side and is no longer bounded below by -1 .

\section{Buyer payoffs}

For $N=1,2$, a bidder's expected payoffs in a hot market can be written as :

$$
\begin{gathered}
H(1)=\frac{1}{1+r d t}\left[(\alpha+\sigma) d t(x-P(0))+\beta d t H(2)+(1-(\alpha+\sigma+\beta) d t) H(1)-d_{b} d t\right] \\
H(2)=\frac{1}{1+r d t}\left[(\alpha+\sigma) d t C\left(T_{1}\right)+\beta d t H(3)+(1-(\alpha+\sigma+\beta) d t) H(2)-d_{b} d t\right]
\end{gathered}
$$

For $N>3$

$$
\begin{aligned}
H(N)= & \frac{1}{1+r d t}[(\alpha+\sigma) d t H(N-1)+ \\
& \left.\beta d t H(N+1)+(1-(\alpha+\sigma+\beta) d t) H(N)-d_{b} d t\right]
\end{aligned}
$$

The solution to these difference equations is given by

$$
\begin{gathered}
H(N)=\eta^{N-2}-d_{b} / r \\
H(2)=\frac{(\alpha+\sigma) C\left(T_{1}\right)-(r+\beta) d_{b} / r}{r+\alpha+\sigma+\beta(1-\eta)} \\
H(1)=\frac{\beta H(2)+(\alpha+\sigma)(x-P(0))-d_{b}}{r+\alpha+\sigma+\beta}
\end{gathered}
$$

where

$$
\eta=\frac{r+\alpha+\sigma+\beta-\left[(r+\alpha+\sigma+\beta)^{2}-4(\alpha+\sigma) \beta\right]^{1 / 2}}{2 \beta}<1
$$

The payoff to waiting is more involved. With probability $\alpha e^{-\alpha t} d t$, a motivated seller enters the market during the cold period after a duration $t$ and triggers an auction with the existing bidders and any other buyers who might have entered during the cold period up to time $t$. In this environment, the buyer's expected payoff in a cold market can be written as

$$
\begin{aligned}
C\left(T_{1}\right)= & \int_{0}^{T_{1}} e^{-(r+\alpha) t}\left[-d_{b}+\alpha \sum_{i=0}^{\infty} \pi_{i}(t)[x-P(i+1)]\right] d t \\
& +e^{-(r+\alpha) T_{1}} \sum_{i=0}^{\infty} \pi_{i}\left(T_{1}\right) H(i+1)
\end{aligned}
$$

Solving gives

$$
C\left(T_{1}\right)=\frac{\Psi_{1}(x-P(0))+\Psi_{3} d_{b}}{1-\Psi_{2}}
$$


where

$$
\begin{aligned}
& \Psi_{1}=A_{1}+A_{2} \\
& \Psi_{2}=\left(\eta-D_{4}\right) A_{3}+D_{4} A_{4}-D_{4} A_{5}+A_{6} \\
& \Psi_{3}=D_{5} A_{3}-D_{5} A_{4}+D_{5} A_{5}-A_{7}-A_{8} \\
& A_{1}=\frac{\alpha\left(1-e^{-(r+\alpha+\beta) T_{1}}\right)}{r+\alpha+\beta} \\
& A_{2}=e^{-(r+\alpha+\beta) T_{1}} D_{1} \\
& A_{3}=\frac{\alpha \beta\left[1-e^{-(r+\alpha+\beta) T_{1}}\left(1+(r+\alpha+\beta) T_{1}\right)\right]}{\eta(r+\alpha+\beta)^{2}} \\
& A_{4}=\frac{\alpha\left(1-e^{-(r+\alpha+\beta(1-\eta)) T_{1}}\right)}{\eta^{2}(r+\alpha+\beta(1-\eta))} \\
& A_{5}=\frac{\alpha\left(1-e^{-(r+\alpha+\beta) T_{1}}\right)}{\eta^{2}(r+\alpha+\beta)} \\
& A_{6}=e^{-(r+\alpha+\beta) T_{1}}\left(D_{2}+\frac{e^{\beta \eta T_{1}}-1}{\eta}\right) D_{4} \\
& A_{7}=e^{-(r+\alpha+\beta) T_{1}}\left(D_{2} D_{5}+D_{3}+\frac{e^{\beta \eta T_{1}}-1}{\eta} D_{5}\right) \\
& A_{8}=\frac{\left(1-e^{-(r+\alpha) T_{1}}\right)}{r+\alpha} \\
& D_{1}=\frac{\alpha+\sigma}{r+\alpha+\sigma+\beta} \\
& D_{2}=\frac{\beta}{r+\alpha+\sigma+\beta} \\
& D_{3}=\frac{1}{r+\alpha+\sigma+\beta} \\
& D_{4}=\frac{\alpha+\sigma}{r+\alpha+\sigma+\beta(1-\eta)} \\
& D_{5}=\frac{r+\beta}{r+\alpha+\sigma+\beta(1-\eta)}
\end{aligned}
$$

Like buyers in markets with excess bidders, sellers in markets with excess goods accept bids that make them indifferent between taking the bid and waiting for the next auction. Since $\alpha$ governs the arrival rate of motivated sellers, the payoff to a lone seller in the market $(N=-1)$ awaiting for the arrival of buyer is given by

$$
Z(-1)=\frac{1}{1+r d t}\left[\alpha d t Z(-2)+\beta d t P(0)+(1-\alpha d t-\beta d t) Z(-1)-d_{s} d t\right]
$$

With other sellers waiting the arrival of a buyer $(N \leq-2)$, sellers are willing to accept a bid that makes them indifferent between selling and waiting in the market, the payoff to $Z(N)$ is 
given by

$$
Z(N)=\frac{1}{1+r d t}\left[\alpha d t Z(N-1)+\beta d t Z(N+1)+(1-\alpha d t-\beta d t) Z(N)-d_{s} d t\right]
$$

The solution to these difference equations is given by

$$
Z(-1)=\frac{\beta P(0)-(r+\alpha) d_{s} / r}{r+\alpha+\beta-\alpha \lambda}
$$

and for $N \leq-2$

$$
Z(N)=Z(1) \lambda^{-N-1}-d_{s} / r
$$

where

$$
\lambda=\frac{r+\alpha+\beta-\left[(r+\alpha+\beta)^{2}-4 \alpha \beta\right]^{1 / 2}}{2 \alpha}
$$

From time to time, entry from one side or the other of the market will occur such that the auction has one bidder and one seller. In this auction, the buyer's offer again makes the seller indifferent between waiting and accepting. For $N \leq-2$

$$
P(N)=Z(N)
$$

Given that buyer entry or seller entry will shift the market, the equilibrium bid with one buyer and one seller can be written as

$$
P(0)=\frac{1}{1+r d t}\left[\alpha d t Z(-1)+\beta d t\left(x-C\left(T_{1}\right)\right)+(1-\alpha d t-\beta d t) P(0)-d_{s} d t\right]
$$

Substitution for $Z(-1)$ gives

$$
P(0)=\frac{\beta D_{6}\left[x-C\left(T_{1}\right)\right]-\left[r D_{6}+\alpha(r+\alpha)\right] d_{s} / r}{D_{6}(r+\alpha+\beta)-\alpha \beta}
$$

where

$$
D_{6}=r+\alpha+\beta-\alpha \lambda
$$

Solving yields

$$
P(0)=\frac{B_{1}\left(1-\Psi_{1}-\Psi_{2}\right) x-B_{1} \Psi_{3} d_{b}-\left(1-\Psi_{2}\right) B_{2} d_{s}}{1-\Psi_{2}-B_{1} \Psi_{1}}
$$

where

$$
\begin{aligned}
B_{1} & =\frac{\beta D_{6}}{(r+\alpha+\beta) D_{6}-\alpha \beta} \\
B_{2} & =\frac{r D_{6}+\alpha(r+\alpha)}{r\left[(r+\alpha+\beta) D_{6}-\alpha \beta\right]}
\end{aligned}
$$


Revenue after a cold phase with one buyer is unchanged

$$
R_{1}\left(T_{1}\right)=\sum_{i=0}^{\infty} \pi_{i}\left(T_{1}\right) P(i+1)-F
$$

whereas

$$
R_{0}\left(T_{0}\right)=\pi_{0}\left(T_{0}\right) Z(-1)+\sum_{i=0}^{\infty} \pi_{i}\left(T_{0}\right) P(i)-F
$$




\section{Data}

This section documents familiar housing market statistics from the Dane County SCWMLS, broadening the reporting on price, sales and time on the market by including new listings and inventories. The same measures are documented from the simulated model and then viewed alongside the Dane County data. The discussion here concentrates on relationships not assessed in the body of the paper.

Table 5 presents the mean values of five SCWMLS variables (in levels) along with their minimum and maximum values. It is worth noting that sales are two thirds the size of listings and less than a quarter of inventory. Table 5 also presents the standard deviation of their logged, detrended and seasonally adjusted values. Note that time on the market is derived from far fewer observations.

Table 5. Means and Standard Deviations

\begin{tabular}{lccccc|c}
\hline & \multicolumn{5}{c|}{ Dane County SCWMLS Data } & Model \\
& Mean & Min & Max & SD & $N$ & SD \\
\hline Price & 209,258 & 116,674 & 292,462 & 0.047 & 132 & $\mathbf{0 . 0 3 4}$ \\
Sales & 423 & 157 & 792 & 0.114 & 132 & $\mathbf{0 . 0 7 4}$ \\
Listings & 636 & 238 & 1241 & 0.119 & 132 & $\mathbf{0 . 0 7 5}$ \\
Inventory & 1847 & 1228 & 3118 & 0.241 & 132 & $\mathbf{0 . 1 4 8}$ \\
Time on market & 66 & 42 & 98 & 0.081 & 72 & $\mathbf{0 . 2 4 5}$ \\
\hline
\end{tabular}

Notes: SCWMLS data in italics. Simulated data in bold face

The lower diagonal half of Table 6 reports the observed contemporaneous correlations among these logged, detrended and seasonally adjusted variables. From the lower half of Table 6, price exhibits positive correlation with listings as with sales. The correlation of price with inventory is negative. Sales and inventory are inversely related whereas listings and inventory correlate positively and prominently.

Given that sales and new listings are weakly correlated, the new listing-inventory relationship makes basic accounting sense. If sales (or new listings) surge, inventory will drop (rise) without a contemporaneous surge in new homes listed for sale (sold). On the other hand, the weak link between sales and new listings appears somewhat at odds with the stock-flow interpretation of trade. The frequency of the SCWMLS data may play a role in depressing observed sales-new listings co-movements. If it takes a few weeks (or a month as suggested by the simulations) between agreeing to exchange and actually completing the deal rather than sales occurring instantaneously, the observed link between sales and the flow of new homes for sales will be depressed in monthly data. 
Table 6. Correlation Coefficients

\begin{tabular}{lccccc}
\hline & Price & Sales & Listings & Inventory & Time on Market \\
Price & 1.0 & $\mathbf{0 . 2 3 7 0}$ & $\mathbf{0 . 4 1 3 7}$ & $\mathbf{- 0 . 4 5 4 9}$ & $\mathbf{- 0 . 3 8 5 4}$ \\
Sales & 0.2188 & 1.0 & $\mathbf{0 . 8 3 8 8}$ & $\mathbf{- 0 . 2 4 3 9}$ & $\mathbf{0 . 3 6 3 2}$ \\
Listings & 0.2665 & .1026 & 1.0 & $\mathbf{- 0 . 2 2 5 8}$ & $\mathbf{0 . 0 1 5 1}$ \\
Inventory & -0.0921 & -0.4264 & 0.5677 & 1.0 & $\mathbf{- 0 . 2 0 8 7}$ \\
Time on market & -0.0851 & 0.3222 & 0.2739 & 0.0537 & 1.0 \\
\hline
\end{tabular}

Notes: SCWMLS data in italics. Simulated data in bold face

The last column in Table 5 reports standard deviations from the simulated data for the $d_{s}^{L}$ specification. ${ }^{30}$ Except for time on the market which should be viewed cautiously, the standard deviations of these simulated statistics are all lower than in the observed data. Missing factors in the model potentially account for this discrepancy. The more relevant point is that the ranking and relative variations compare well with the data. ${ }^{31}$

The upper diagonal half of Table 6 reports the contemporaneous correlations from the simulations for $d_{s}^{L}$. The initial impression is mixed but given the data limitations, not unexpected. Many listings never sell and apparently are withdrawn, whereas inventory will include houses that are in the process of completing an agreed sale.

Contemporaneous inventories are inversely related to price in the model as one might plausibly anticipate when many sellers are waiting for buyers. This shows up with lagged inventory in the data. New listings in the model correlate very closely with sales and closely with price. In the SCWMLS data, however, new listings and sales correlate very weakly whereas new listings and price exhibit less co-movement than in the model. In the model a new listing will often result in an immediate sale (and frequently with more than one bidder) thereby generating the strong positive co-movements. The decision to enter rests on a high probability of a sale in a competitive auction. In the model, the sale occurs immediately hence the tight link between new listings and sales. In practice, it takes time to carry out a home sale and such delays potentially generate such a discrepancy even if the model captures the essential trading process. Using quarterly data Ngai and Sheedy (2015) report correlations of 0.602 and 0.850 for new listings with price and with sales respectively which match up well with the model. Moreover, when the listing does not sell immediately, sales are lower so inventory rises. In both the data and the simulations, inventory and sales are inversely correlated with similar magnitudes.

Now consider new listings and inventory which are positively correlated in the data but negatively in the simulations. In the model, if inventories become high, many markets will experience cold spells without relaxed seller entry, hence the negative co-movement between listings and inventory. Cold spells accompanying high inventories and low entry will have lower

\footnotetext{
${ }^{30}$ The mean for price is not comparable. The simulated model roughly matches mean sales for Madison. Mean inventory equals 77 which for good reasons is much lower than in Madison.

${ }^{31}$ Ngai and Sheedy (2015) report several figures similar to the ones reported here. Using seasonally adjusted, trending quarterly data, they find new listings are more volatile than sales whereas the Dane County and model figures are very close. Ngai and Sheedy also report time to sell (not time on market), prices, and inventories. Díaz and Jerez (2013) also present a number of overlapping measures based on filtered, quarterly figures.
} 
sales thereby contributing to the negative inventory-sales relationship. In practice, sales do not correlate - at least immediately - with listings as in the model, which, as discussed, yields a more direct accounting relationship driving the observed listings-inventory data.

The relationships between time on the market and the non-price variables in the model involve a number of interactions that also deserve discussion even if the measure of time on the market from the SCWMLS data is limited. To organize ideas, first suppose inventories are below average indicating there are relatively few markets experiencing cold spells of declined entry. New listings will tend to be high as relaxed buyers are more likely to enter. Sales too will tend to be above normal but these sales will not greatly affect time on the market. Sales of homes that occur immediately after seller entry have no effect on the time on the market as these homes come and go without quickly. Likewise, a sale from the existing stock of homes does not lower the average time on the market. If such a sale is a random selection, it removes an average duration home and hence has no immediate impact on the average time on the market. After the sale, however, average time on the market in the existing stock continues to increase. If new listings from entry of relaxed sellers are high due to low inventories and resulting sales are high, time on the market can still rise and result in a positive and non-negligible sales-time on the market co-movement as observed in the simulated as well as in the SCWMLS data. ${ }^{32}$

Now suppose inventories of unsold homes are high which will deter entry of many relaxed sellers. A composition effect from the exogenous motivated seller entry potentially explains the inventory-time on the market inverse co-movement found in the model. Average time on the market falls (or rises more slowly) as new listings from such sellers do not find a existing buyer and are added to the stock of homes for sale. As entry without an immediate sale is essentially exogenous and scattered across all markets, it is more common when inventories are high. With an above normal number of unsold homes, new listings by motivated sellers become more likely not to sell immediately driving down average time on the market. The process in the observed data may be more involved as actual trade takes some time and new listings that sell quickly are sometimes around long enough to affect time on the market as well as inventory measures.

\footnotetext{
${ }^{32}$ Here the distinction between time on the market and time to sale might be particularly relevant. Ngai and Sheedy (2015) find a strong strong negative link between new listings and time to sell. They further report very little correlation between inventories and new listings.
} 